\title{
EXPERIMENTS ON THE NONLINEAR CHARACTERISTICS OF NOISE PROPAGATION FROM LOW AND \\ MODERATE REYNOLDS NUMBER \\ SUPERSONIC JETS
}

\author{
BY \\ JAMES ANTHONY GALLAGHER \\ Bachelor of Science \\ University of Manchester \\ Manchester, England
}

1979

\footnotetext{
Submitted to the Faculty of the Graduate College of the Oklahoma State University in partial fulfillment of the requirements for the Degree of MASTER OF SCIENCE

May, 1981
} 
Thesis

1981

G162e cop. 2 


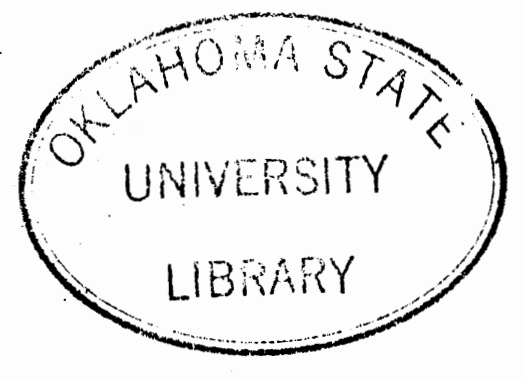

EXPERIMENTS ON THE NONLINEAR CHARACTERISTICS

OF NOISE PROPAGATION FROM LOW AND

MODERATE REYNOLDS NUMBER

SUPERSONIC JETS

Thesis Approved:

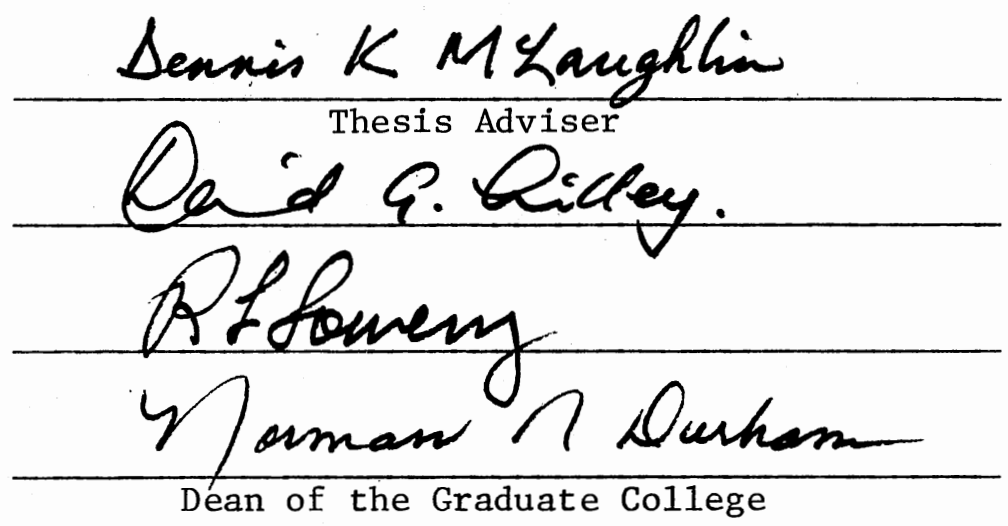




\section{ACKNOWLEDGEMENTS}

The author wishes to express his appreciation to his major advisor Dr. D. K. McLaughlin, and to his other committee members, Dr. D. G. Lilley and Dr. R. L. Lowery, for their advice and guidance with regard to this study. Deep appreciation is also expressed to Mr. T. F. Hu for his helpful guidance and assistance concerning the acquisition of much of the data used in this study. Thanks is also extended to Ms. Karla Burge for the typing of this thesis.

Finally the author would like to acknowledge the financial support provided for this study by the National Aeronautics and Space Administration, Langley Research Center on Grant Number NAG 1-10. 


\title{
TABLE OF CONTENTS
}

\begin{abstract}
Chapter Page
I. INTRODUCTION . . . . . . . . . . . . . . . . . . 1

II. EXPERIMENTAL CONSIDERATIONS. . . . . . . . . . . . . 6

III. MEASUREMENT PROCEDURES . . . . . . . . . . . . . . . . . 9

IV. EXPERIMENTAL RESULTS . . . . . . . . . . . . . . 12

V. SUMMARY AND CONCLUSIONS. . . . . . . . . . . . . 22

SELECTED BIBLIOGRAPHY . . . . . . . . . . . . . . . . . 23

APPENDIX A - FIGURES. . . . . . . . . . . . . . 26

APPENDIX B - TABLE. . . . . . . . . . . . . . . 52
\end{abstract}




\section{TABLE}

Table

Page

I. Nonlinear Propagation Results . . . . . . . . . . 53 


\section{LIST OF FIGURES}

Figure

Page

1. The Effect of Nonlinear Propagation on a Sinusoid . . . . . 27

2. Schematic of Overall Facility . . . . . . . . . 28

3. Schematic of Jet Test Facility. . . . . . . . . . 29

4. Electronic Arrangement for Digitization . . . . . . . 30

5. Coordinate Systems Diagram. . . . . . . . . . 31

6. Facility Absorption Calibration Curves (15KHz). . . . . . 32

7. Facility Absorption Calibration Curves (30KHz). . . . . . 33

8. Sound Pressure Level Contours for a $M=2.5$ Jet . . . . . 34

9. Typical Oscilloscope Trace of Microphone Signals. . . . . 35

10. Waveforms From a Low Reynolds Number $M=2.5$ Excited Jet. . 36

11. Microphone Spectra From a Low Reynolds Number $\mathrm{M}=2.5$ Excited Jet . . . . . . . . . . . 37

12. Waveforms From a Low Reynolds Number $M=2.1$ Excited Jet.. . 38

13. Microphone Spectra From a Low Reynolds Number $\mathrm{M}=2.1$ Excited Jet . . . . . . . . . . . . . 39

14. Waveforms From a Low Reynolds Number $M=2.5$ Jet. . . . . 40

15. Microphone Spectra From a Low Reynolds Number $M=2.5$ Jet . . 41

16. Waveforms From a Low Reynolds Number $M=2.1$ Jet. . . . . 42

17. Microphone Spectra From a Low Reynolds Number

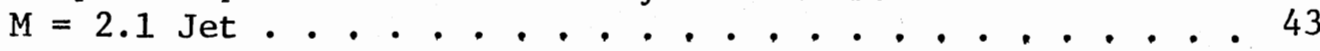


18. Sound Pressure Directivity Plots of a Moderate Reynolds Number $\mathrm{M}=2.1$ Jet. . . . . . . . . . . . . 44

19. Waveforms From a Moderate Reynolds Number $M=2.5$ Excited Jet, 45

20. Microphone Spectra From a Moderate Reynolds Number $\mathrm{M}=2.5$ Excited Jet. . . . . . . . . . . . 46

21. Microphone Spectra From a Moderate Reynolds Number $\mathrm{M}=2.1$ Excited Jet. . . . . . . . . . . . 47

22. Microphone Spectra From a Moderate Reynolds Number

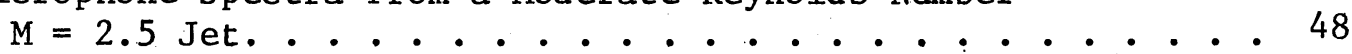

23. Waveforms From a Moderate Reynolds Number $M=2.5$ Jet. . . 49

24. Waveforms From a Moderate Reynolds Number $M=2.1$ Jet. . . . 50

25. Microphone Spectra From a Moderate Reynolds Number Jet . . . 51 


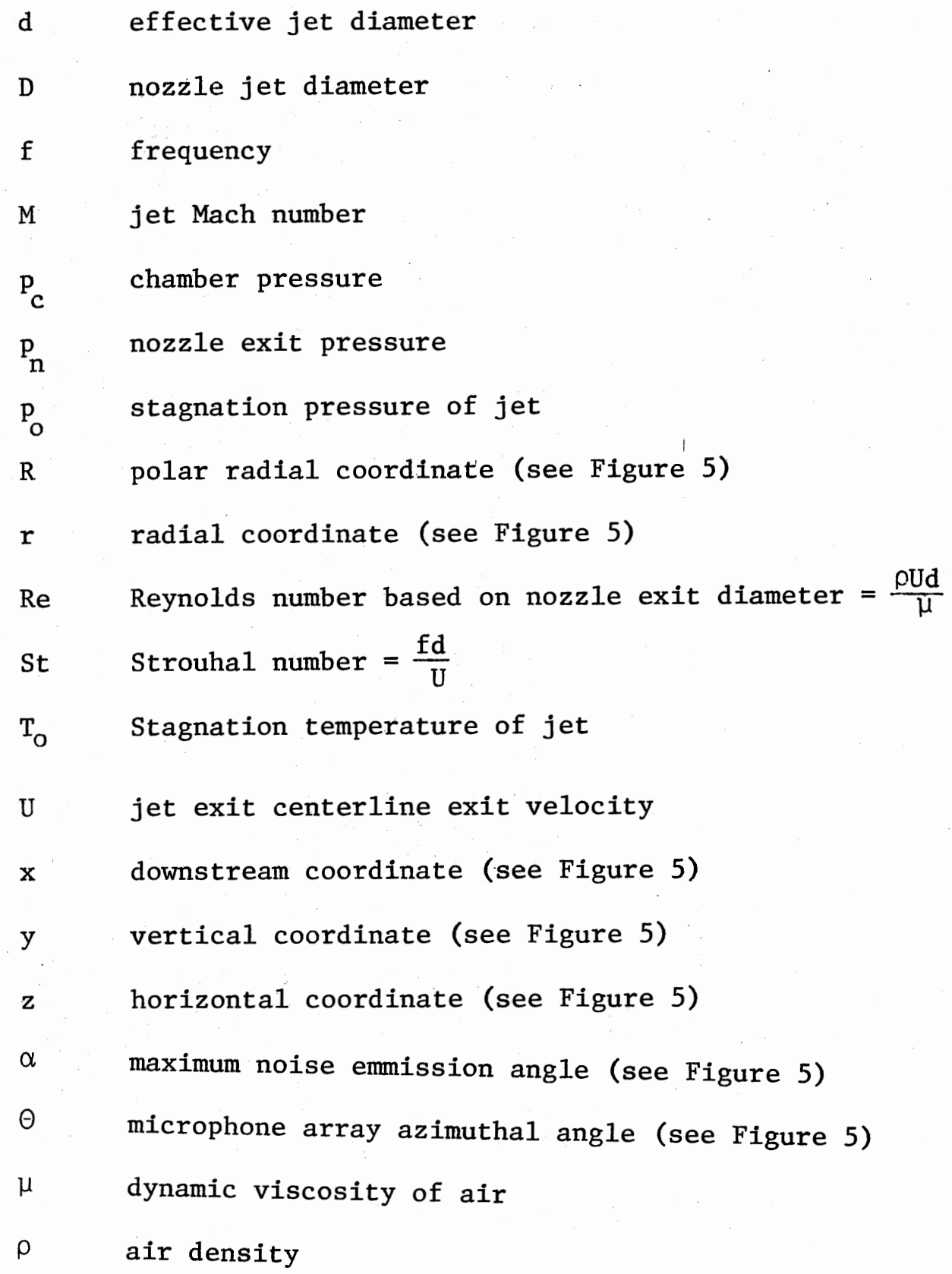


CHAPTER I

\section{INTRODUCTION}

The implementation of the Federal Aviation Regulation (FAR), Part 36, which controls the maximum permissible noise level attained on aircraft take-off and landing, has tended to emphasize the need for noise tests on ground-based rigs, since these are used in the estimation of the overall noise that may be produced by an aircraft under design. However, anomalies have been found when these ground-based rig predictions are compared with actual flight noise data. The high frequency end of the noise spectra is found to be underpredicted in the very far field at high thrust level conditions. The Effective Perceived Noise Leve1 decibe1 (EPN dB) is the unit used to measure the annoyance of the noise, and the unit used in FAR Part 36. It has a significant weighting factor for high frequencies. Consequently, the underprediction of the high frequency end of the spectrum can lead to a predicted noise level that is lower than the actual flight noise data. This situation is of serious consequence to both the airframe and aircraft engine manufacturers.

Spectral anomalies may be related to nonlinear propagation distortion of sound waves as they travel through the air. Although the effect of nonlinear propagation in jet noise has been widely accepted, little research seems to have been undertaken in this area. In fact, it seems that the theory far exceeds confirming experimental evidence, Little relevant data from actual jet engines or model jets have been published 
in the open literature.

Any pressure wave which propagates in air will tend to distort. This occurs because the pressure peaks travel faster than the pressure troughs. Figure 1 (Appendix A) shows an illustration of this. Starting with a pure sinusoidal pressure wave in space, during propagation the pressure peaks travel faster than the pressure troughs, and begin to catch up with them. The compression phase of the wave thus steepens while the expansion phase becomes less steep. Eventually the compression phases steepen to form shock waves and the propagating wave becomes similar to the waveform in Figure $1(\mathrm{c})$. The pressure-time waveshape is the mirror image of this, and is similar to the $N$-type waveshape associated with the sonic boom.

Burns [1] demonstrated the effect of nonlinear propagation distortion by measuring a propagating inverted sawtooth wave in air which distorted into a pure sine wave and then continued to propagate and distort into a shock-containing regular sawtooth wave.

Probab1y the most documented research on nonlinear propagation has been undertaken by Webster and Blackstock [2]. Using a spherical source, they found that nonlinear effects in the form of wave steepening are measurable in discrete tone acoustic waves of $146 \mathrm{~dB}\left(\right.$ re $\left.2 \times 10^{-5} \mathrm{~N} / \mathrm{m}^{2}\right)$. Since the nearfield noise levels of supersonic jets of Mach number 2 typically exceed this, it might be expected that nonlinear propagation effects would be measurable in their noise fields, However, the acoustic spreading properties of a jet are very much different and much more complex than the spherical spreading from a point source. It is more reasonable to assume that a model jet will more nearly model the acoustic propagation of a real jet. This is the major motivation for the present study. 
Webster and Blackstock [2] found that there were two distinct stages in the overall effect of nonlinear propagation. Stage I is wave-steepening and the formation of shock waves, leading to an increase in the harmonic content or higher end of the frequency spectrum. Stage II is the merging of shock waves to give a waveform which has a fewer number of zero crossings, and is associated with an increase in the lower end of the frequency spectrum. Thus, both of these nonlinear effects work to broaden the outer limits of "the frequency spectrum, at the expense of the middle.

Most of the earlier work on nonlinear propagation was carried out using plane waves propagating in tubes [3-6], at sound levels in excess of $140 \mathrm{~dB}$. The advantage in using plane waves is that the distortion occurs faster because the waves remain more intense over longer distances. In this case, Stage I and II type behavior was found. When using a spherical source the waves have to travel much farther before they become distorted and then atmospheric absorption generally has time to dissipate any shocks formed. Stage II in this case is not usually attained [7-9].

The amount of published theoretical work on nonlinear propagation far exceeds the amount of comparable experimental data. Many of these theories lack experimental verification, Blackstock [10], using measured noise from an actual jet engine as input to a computer program, was able to "computer propagate" the noise and predict the amount of distortion during the propagation. His model was much simplified and neglected the effects of atmospheric absorption. His results predicted non-linear propagation to be a significant factor in jet noise, although there has been no experimental verfication of this. 
Crighton and Bashforth [11] used a weak nonlinear perturbation theory to calculate a propagating broadband jet noise signal. Their results suggest that nonlinear effects are important even at moderate sound pressure levels. Again however, rigorous experimental verification has not been obtained for comparison purposes.

The basic aim of this thesis is to investigate the role nonlinear propagation may play in jet noise. This can be achieved by measuring the propagation of noise away from high speed jets, and documenting the extent of the properties of the propagation which are characteristic of nonlinear distortion. Such characteristics are:

1. Steepening of the propagation waveshape

2. An increase in the higher frequency content of the spectrum

3. A decrease of zero crossings of the waveform due to shockmerging

4. An increase in the lower frequency content of the spectrum due to $(3)$.

The data from both natural and excited Mach number 2.1 and 2.5 jets will be used for these measurements. The major unique feature of the experiments is that they were performed in the Oklahoma State University low pressure anechoic test facility. Jets operating in this facility have unusually low Reynolds numbers in the range $\operatorname{Re}=9,000$ to 50,000 which compares with $\operatorname{Re}=10^{6}$ to $10^{7}$ in conventional model jet test facilities. The jet experiments in the low pressure facility (Figure 2) offer an advantage not available in most facilities designed to study jet noise. These relatively lower Reynolds number experiments require a lower pressure (approximately $1 / 100-1 / 10$ atmospheres) and correspondingly low density. Under low Reynolds number conditions, the noise radiation from the jet is discrete in frequency and very intense along the maximum 
noise emission angle. In some cases the discrete frequency nature of the noise makes it more convenient and/or possible to determine important noise generation and propagation features, not possible with conventional high Reynolds number, broad spectra jets.

An additional advantage of operating the jets at low to moderate Reynolds number is that it is possible to artifically excite the jet with a pure tone disturbance generated by a glow discharge excitation device previously reported in references [12 and 13]. Excitation of low Reynolds number jets tends to make the radiated noise even more discrete as it phase locks to the excitation. This discrete frequency portion of the noise is being used to study nonlinear propagation effects. The excitation device can also be used with the moderate Reynolds number jets to produce a concentrated peak in the noise spectrum which is naturally broad band like it's conventional high Reynolds number counterpart. 
CHAPTER II

EXPERIMENTAL CONSIDERATIONS

General Facility

This study was conducted in the Oklahoma State University high speed jet noise test facility. A schematic of the overall facility is shown in Figure 2. The jet air supply is first dried and then stored in a 1.8 cubic meter supply tank. A muffler reduces the valve noise from an upstream throttling valve, while a stilling section reduces the turbulence level and straightens the flow. The air exhausts into an anechoic chamber via a contoured contraction and a supersonic nozzle. The chamber has dimensions of $114 \mathrm{~cm} \times 76 \mathrm{~cm} \times 71 \mathrm{~cm}$ and is 1ined with a $5 \mathrm{~cm}$ thick layer of Scott Pyrell Acoustical Foam, producing an anechoic environment for frequencies above one kilohertz (Figure 3).

Two different supersonic axisymmetric nozzles with exit diameters (D) of $6.86 \mathrm{~mm}$ and $7 \mathrm{~mm}$, having design Mach numbers of 2.5 and 2.1 respectively, were used in these experiments. The nozzle contours were calculated using a NASA computer program [14] employing the method of characteristics. The contour designs also included a boundary layer correction as determined by the method of Rott and Crabtree [15].

The jet facility is operated by evacuating its downstream section. The chamber pressure is controlled by adjusting a variable throat diffuser upstream of a $0.1 \mathrm{~m}^{3} / \mathrm{sec}$ vacuum pump. The Reynolds number of the 
flow is varied by adjusting the stagnation pressure, $P_{0}$, upstream of the nozzle.

The facility test chamber is equipped with an electrically driven, remotely controlled, probe drive system capable of translation in three orthogonal directions. Precision ten turn potentiometers provide DC voltages proportional to the probe location. This system allows accurate and repeatable probe positioning when care is taken to eliminate mechanical backlash. In addition to the probe drive system, stationary probe mounts can be attached to the top and sides of the test chamber, prior to an experiment, allowing probe locations anywhere in the test chamber volume.

\section{Instrumentation}

Pressure measurements were made with a silicone oil (specific gravity of 0.93) manometer and a mercury manometer, both referenced to a vacuum of 30 microns of mercury, absolute pressure. Pressure taps were located at various positions in the facility to measure the stilling chamber stagnation pressure, nozzle static pressure and test chamber pressure. By controlling both the stilling chamber stagnation pressure, and the test chamber pressure, the required type of jet expansion was obtained. The stagnation temperature upstream of the nozzle was monitored using an ironconstantan thermocouple.

The jets' acoustic fields were measured using Bruel and Kjaer $3.2 \mathrm{~mm}$

diameter type 4138 condenser microphones. Based on factory specifications, the microphones were assumed to have omni-directional response $\pm 3 \mathrm{~dB}$ for angles $\pm 90^{\circ}$ to the microphone axis and for frequencies up to $60 \mathrm{kHz}$. Calibration of the microphones was performed using a B and $\mathrm{K}$ type 4220 
piston phone,

The normal hot-wire probe used in this study was a DISA subminiature probe mounted on a slender brass wedge. A frequency response of not less than $50 \mathrm{kHz}$, as determined by square wave response tests, was obtained using a DISA 55M01 constant temperature anemometer main frame and a DISA 55M10 standard bridge.

On all the microphone and hot-wire measurements, the signals were band-pass filtered from $1.5 \mathrm{kHz}$ to $70 \mathrm{kHz}$ to remove chamber and microphone resonances. The filters used were Multimetrics type AF-120, having a $48 \mathrm{~dB} /$ octave rol1-off when used in the band-pass mode.

A Tektronix 7L5 spectrum analyzer was used to observe the microphone and hot-wire spectra during the course of the experiments. The microphone and hot-wire signals were recorded using a Honeywel1 7620 magnetic tape recorder containing wide band FM electronics. The tape recorder has a flat frequency response up to $80 \mathrm{kHz}$ at a tape speed of 120 inches per second, with a $46 \mathrm{~dB}$ signal to noise ratio.

Data reduction of the microphone and hot-wire signals was accomplished by transferring the data on tape to Oklahoma State University's IBM 370/159 digital computer. A Biomation 1015 four channel digital waveform recorder sampled the signals from the Honeywell tape recorder. In order to get an optimum frequency response/record time from the Biomation, the tape was played back at a speed slower than it had been recorded. The digital output of the Biomation was then sent to a microprocessor which in turn transmitted data by phone line to the IBM 370/159, Figure [4]. The data were then processed on the IBM 370 system. 
CHAPTER III

MEASUREMENT PROCEDURES

In all experiments, the microphones were located in the maximum noise emission direction of the jet. Previous measurements $[16,17]$ have thoroughly documented the acoustic fields of the low and moderate Reynolds number jets. Further acoustic measurements determined the maximum noise emission angles for run conditions not previously encountered. Figure [5] shows the radial location of the microphones in relation to the jet axis. The microphones were located along a plane $45^{\circ}$ to the jets vertical and horizontal planes, allowing measurements over a longer propagation distance before encountering contamination from the wall of the chamber.

After the first initial experiments, the microphones and their complete associated channels were permuted between each position to ensure the results were not due to electronic phenomena.

\section{Artificial Exciter and Hot Wire}

The role of the artificial exciter was essentially to phase-lock the natural instabilities of the jet. The tungsten electrode in the discharge device was normally biased to a 500 volt negative potential by a DC power supply, The current drawn by the glow was approximately $0.4 \mathrm{MA}$ in the low Reynolds number experiments and around 4-6 MA in the moderate Reynolds number cases. The electrode on the glow discharge was orientated so that 
it was in the same plane as the microphone array. The excitation frequency was tuned to provide the maximum amplification of the jet's natural instability and to give as low a second harmonic content as possible in the flowfield flucuations. This was achieved by introducing a hotwire into the flow near the end of the potential core, and monitoring the frequency spectra of its signal.

Tape and Digital Recorder Procedure

Care was taken to clean and demagnetise the tape path and heads before each major recording. A test tape was used to monitor possible changes in the tape recorder's fidelity. During recording, the tape recorder ran at 120 inches per second (ips). On playback, for purposes of accurate digitization, this was decreased to 30 or 60 ips, depending on the run condition recorded. The sampling rate of the Biomation 1015, when used as a digitizer, was adjusted to $100 \mathrm{kHz}$. The record length, using its single channel mode is 409610 bit words. When the playback speed of the tape is 60 ips, the effective "real-time" digitization rate is $200 \mathrm{kHz}$. This gives approximately thirteen data points per wave on a single $15 \mathrm{kHz}$ signal, $15 \mathrm{kHz}$ being the approximate natural instability frequency of the jets run at low Reynolds numbers. The jets run at moderate Reynolds numbers have a higher frequency content and their waveshape is harder to define. Recordings from these jets were played back at 30 ips, resulting in a greater effective digitization rate. The tape recorded signals from each microphone were digitially recorded separately, in order to receive a long record time from the Biomation 1015. A trigger pulse on another channel of the tape was used to initiate the digitization and, hence, the synchcronization of the signals. "Time- 
shifting" of the signals, to take account of the propagation time-lag between microphones, was performed during data reduction on the IBM 370 computer. The time shifted signals used to compute the spectra consisted of 3696 words.

\section{Pressure Conditions}

The jets, in most cases, were run in the perfectly balanced condition. However, if the jet proved difficult to phase lock to the excitation or did not show a prominent natural instability frequency, the pressure condition was changed until the jet was slightly underexpanded. The Mach number, in the underexpanded cases, was never above five percent from the design Mach number, suppressing any shock screech phenomena associated with underexpanded jets. An assortment of pressure conditions and excitation frequencies were used to find the best amplification of the instability frequency. 
CHAPTER IV

EXPERIMENTAL RESULTS

Facility Calibration

Although operating jets at low Reynolds numbers has a distinct advantage, (see Chapter I) there is also an inherent disadvantage. Low density and low pressure conditions result in an abnormally high absorption rate which, as for atmospheric conditions, is not constant but increases with increasing frequency. However, it has been found [18] when nonlinear effects are present that the "effective" absorption attenuation (i.e. the decibel level drop in the upper end of the frequency spectra) is much less. The frequency spectra do not seem to suffer a larger attenuation at the higher frequencies.

Atmospheric absorption tends to smooth out the waveform and actually works against the wave steepening distortion effect. In order to obtain an estimate of the magnitude of the absorption attenuation, sound pressure leve1 (SPL) measurements were made at varying distances from a noise source located in the test chamber, under test chamber pressures similar to those encountered in normal run conditions. The chamber was supplied with dried air before being pumped down to pressure. A horn driver was used as a source. The driver was excited at $15 \mathrm{kHz}, 30 \mathrm{kHz}$ and $45 \mathrm{kHz}$ (the harmonic frequencies of interest in our $\mathrm{M}=2.5 \mathrm{jet}$ excited at $\mathrm{St}=0.16)$. A microphone, attached to the probe drive system, 
measured the SPL along the horizontal axis of the driver.

The results are shown in Figures 6 and 7 . Two main problems hindered their interpretation:

(a) The acoustic impedance match between the air and driver change as the pressure is decreased, resulting in a much lower source output at lower pressure. This problem is accentuated even more by the fact that the $B \& K 3.17 \mathrm{~mm}$ microphones used in this study are insensitive below $76 \mathrm{~dB}\left(\right.$ re $2 \times 10^{-5} \mathrm{~N} / \mathrm{m}^{2}$ ). The sound pressure level at one inch from the driver was measured to be $124 \mathrm{~dB}$ at one atmosphere, however when the pressure was reduced to $1 / 10$ of an atmosphere the sound pressure level reduced to $105.6 \mathrm{~dB}\left(\right.$ re $\left.2 \times 10^{-5} \mathrm{~N} / \mathrm{m}^{2}\right)$. The resulting attenuation of the signal as the microphone travels away from the driver soon puts the signal level close to the verge of the capability of the microphone. Measurements at a pressure of 1/100 of an atmosphere were abandoned because of this problem.

(b) Although the data are in reasonable agreement with $6 \mathrm{~dB}$ per doubling of distance, for point source spreading, at distances greater than seven inches an unknown effect enters into the results, The anomalous results may be due to diffraction effects of the driver lip. Similar results have been reported previously [7]. Allen found in his work that a wind induced by the intense source caused a refraction of the sound, leaving a 'sound shadow', Repeated attempts to find the cause of the irregulardata were unsuccessfu1. Phase measurements did show a gradual change in phase as the microphone moved from the source to seven inches, however after this point erratic changes in phase were encountered, making an actual recording of the phase impossible. 
It had been expected that the atmospheric attenuation would increase with decreasing density as suggested by [19]. Although the driver did seem to behave as a point source, a short distance away, the data cannot confidently be used to render a value for the atmospheric attenuation, due to its irregularity after seven inches. However, the reasonably long region of spherical spreading, represented by a $6 \mathrm{~dB}$ per doubling of distance, indicates that there is not an abnormally high absorption rate in the test chamber under run conditions. It can be assumed therefore, that the value of atmospheric absorption will not be so high as to prevent any possible steepening of the intense sound generated by our supersonic jets.

\section{Low Reynolds Number Jet Results}

When measuring sound pressure levels in the low pressure chamber, the reference pressure is scaled to the ambient pressure in the chamber. This scaling allows comparison with sound pressure levels measured at atmospheric conditions. The scaling is accomplished by calculating the sound pressure level in the following manner:

$$
\mathrm{SPL}=20 \log _{10} \frac{\mathrm{p}_{\mathrm{rms}}^{\prime}}{\left(2 \times 10^{-5} \mathrm{~N} / \mathrm{m}^{2}\right)\left(\mathrm{p}_{\mathrm{c}} / \mathrm{p}_{\mathrm{atm}}\right)}
$$

Figure 8 shows a typical sound pressure level contour diagram for a $M=$ 2.5 low Reynolds number jet excited at $\mathrm{St}=0.16$. The diagram also indicates the location of the first two microphones with asterisks. In both the $M=2.5$ and $M=2.1$ cases, the $S P L$ is at least $150 \mathrm{~dB}$ along the maximum noise emission path, twenty-five diameters from the jet exit. 
Figure 9 shows typical oscilloscope traces of microphone signals from a low Reynolds number $(\operatorname{Re}=8,700) \mathrm{M}=2,5$ jet excited at $\mathrm{St}=0.16$. The microphones were located at 30 and 80 diameters. As can be seen, the waveform clearly steepens as it propagates, forming a series of strong shocks. Note that the output signal of the type of condenser microphone used is negative-going for positive pressure on the diaphragm [20]. This results in a "mirror image" signal. The wave is seen to steepen to the right instead of to the left. On all further waveforms the plots have been inverted to show the actual pressure change on the diaphragm of the microphone.

Figure 10 shows the actual individual signals corresponding to the triggered oscilloscope traces in Figure 9. The waves have been "timeshifted" by computer to account for the delay time in propagating from one microphone to another. These waveforms represent a portion of the digitally recorded signal used to calculate the spectrum. As indicated by the oscilloscope trace, the waveform has steepened slightly by the time it reaches the first microphone at 30 diameters. The wave continues to steepen until, at 80 diameters, a series of shocks have formed, giving a N-type waveform.

In an effort to quantify the amount of wave steepening present in a wave, a wave steepening factor (WSF) has been defined. As the wave has been digitized, the slope between any two points can be calculated. The' wave steepening factor has been defined as the modulus of the average negative slope (the time average of the negative slope portion of the waves) divided by the average positive slope (defined similarly to the average negative slope). This will give a wave steepening factor of approximately unity for a pure sinusoidal wave, and a wave steepening 
factor close to zero for a pure sawtooth or N-type waveform. Thus a decreasing WSF should indicate wave steepening.

The waves in Figure 10 have a WSF which decreases from 0.68 at 30 diameters to 0.47 at 80 diameters. The WSF does, therefore, seem to be sensitive to wave steepening.

As would be expected, there is no zero crossing decrease in the propagating waveforms shown in Figure 10. The shocks produced are essentially of the same strength and hence travel at similar velocities. A larger distance would be needed before any shock merging and eventual zero-crossing decrease could be observed.

The spectra associated with the signals of Figure 10 are shown in Figure 11. Comparison of the spectra shows that there is a slight increase in the harmonic content of the waveform as it propagates. This is quite contrary to what would be expected to happen, with regard to atmospheric absorption which would tend to attenuate the higher frequencies at a greater rate.

Figure 12 shows waveforms measured from a $M=2.1$ jet excited at St $=0.19$. Again as in the $M=2.5$ jet, the wave steepens as it propagates and for the waves shown the WSF decreases from 0.6 at 30 diameters to 0.47 at 80 diameters. Again the number of zero crossings remain essentially constant. Generally, there is little decrease in the number of zero crossings in the excited jet cases as the shocks produced are all of similar strength.

The waveform from a $M=2.5$ natural $j$ et is shown in Figure 14. As can be seen the waveform is not as periodic as in the excited jet cases, however the waveform is seen to smooth out as it propagates and there is an obvious decrease in zero crossings at 80 diameters, For this partic- 
ular waveform, the WSF decreases from 0.88 to 0.85 from 30 to 50 diameters but then increases again to 0.89 , indicating that the wave steepens in traveling from 30 to 50 diameters, but tends to smooth out after this.

The frequency spectra (Figure 15) show an increase in the relative amplitude of the second harmonic as the wave propagates away from the jet. The spectrum at 80 diameters also has a significant lower frequency content due probably to two effects. First of all the number of zero crossings in the waveform decreases by seven percent from 30 to 80 diameters from the jet exit. This decrease in zero crossings is consistent with the lifting of the low end of the frequency spectrum. This effect is characteristic of nonlinear acoustic propagation. However, a second effect is no doubt present. Further downstream the jet turbulence contains more low frequency content which is perhaps radiating preferentially towards the furthest downstream microphone at $\mathrm{R} / \mathrm{d}=80$.

Figure 16 shows the waveform propagated from a low Reynolds number unexcited $M=2.1$ jet. The waveform is more discrete than the $M=2.5$ natural jet and thus there is no noticeable change in the number of zero crossings. The WSF increases slightly from 30 to 80 diamters indicating that the wave is tending to smooth out. The associated frequency spectra (Figure 17) show very little change as the wave propagates, indicating that the wave steepening and absorption smoothing are tending to balance each other. In summary, no clear evidence of nonlinear acoustic propagation is apparent in the case of the unexcited low Reynolds number $M=2.1$ jet. It seems that the nonlinear distortion effects are weaker in the $M=2.1$ unexcited jet because of low sound pressure 1evels, in comparison with the $M=2.5$ jet, and are overcome by the atmospheric 
absorption effect in this low pressure condition.

Table I in Appendix B presents a summary of all the zero crossing defect, wave steepening factor and relative second harmonic data for several segments of taped microphone measurements recorded during experiments of different jet conditions. The segments of the taped data labeled A, B, C, D correspond to digitized segments extracted from the analog tape recordings of the microphone signals and the imposed triggering signal. The segments, which contain 4096 characters and represent only a fraction of a second of real time recording, are extracted from the tape recording with a spacing of 30 seconds between them. Consequently the correspondence of the data in Table I from one segment to another provides a measure of the repeatability and confidence in the data.

The low Reynolds number test data have been discussed above and the moderate Reynolds number jet data will be discussed in the next section.

Moderate Reynolds Number Jet Results

Although the acoustic fields of the low Reynolds number jets have been documented previously $[16,17]$, the $M=2.5$ jet had not been operated in the moderate Reynolds number regime before. Sound pressure level measurements were made at points along arcs of 20,30 and 40 diameters from the jet exit to determine the maximum noise emission path for placement of the microphones. Figure 18 shows the resulting sound pressure level directivity plot at 30 diameters. The maximum noise emission angle at 30 diameters is approximately $25^{\circ}$ for the natural jet and $30^{\circ}$ when the jet is excited. This is consistent with the maximum noise emission angles measured for other supersonic jets in our laboratory $[13,16,17]$. 
Operation of the jets at a moderate Reynolds number, in the range from $\operatorname{Re}=50,000$ to $\operatorname{Re}=70,000$, is advantageous to this study. In the unexcited jet case the radiated noise is broad band in character, quite similar to conventional high Reynolds number jets (see for example Troutt [17]). However when a moderate Reynolds number supersonic jet is subjected to excitation with the glow discharge device, additional radiated noise concentrated at the frequency of excitation tends to dominate the pressure signals. Consequently the signals look similar to their low Reynolds number counterparts and any apparent wave steepening can be noted and quantified.

Increasing the Reynolds number of the jet also increases the density and consequently lowers the atmospheric absorption. Since atmospheric absorption tends to work against wave steepening, (and the atmospheric absorption has been lowered), it would be expected that wave steepening would occur much earlier in the acoustic field. However, this is not the case as can be seen from the waveforms of the $M=2.5$ jet excited at St $=0.29$ (Figure 19). The waveforms are essentially symmetric, as indicated by the corresponding wave steepening factors in Table I. They do, however, tend to exhibit slight steepening during propagation as indicated by a decrease in the WSF from 1.14 at 30 diameters to 0.92 at 50 diameters. This slight steepening does however produce quite a significant increase in the relative second harmonic content (Figure 20). At 80 diameters the second and third harmonics have been greatly attenuated, indicating that atmospheric absorption has begun to cancel out the wave steepening effect. There is little significant zero crossing decrease of the waveforms in Figure 19 betwen 30 and 80 jet diameters, as indicated in Table I. Again as in the lower Reynolds number case the wave has 
been discretized and hence a longer propagation distance would be needed before shock merging could take place.

A similar result also occurs in the $M=2.1$ jet, excited at $\mathrm{St}=$ 0.19. In this case the large second harmonic content of the spectra (Figure 21) is of a higher amplitude than the fundamental. This is not due to nonlinear propagation but is caused by the instabilities around St $=0.3$ being very powerful noise generators (17). The feature to notice, however, is the increased frequency content around a Strouhal number of 0.1 . Again, there seems to have been a production of lower frequencies in the propagation of the sound from a polar radius of 30 jet diameters to 80 jet diameters.

The typical natural moderate Reynolds number jet has a frequency spectrum that is very broad band. There is 1ittle discernable dominant frequency content in the acoustic field, unlike the lower Reynolds number jets. Figure 22 shows the essentially broad-band frequency spectra of a $M=2.5$ natural jet measured at 30,50 and 80 diameters. There is an obvious growth of low frequency content as the noise propagates away from the jet, as reported previously by Troutt (17). The low frequency growth is also accompanied by a 16 percent decrease in the number of zero crossings of the waveform (Figure 23) as it propagates from 30 to 80 diameters. A 14 percent decrease in zero crossings is found in the $M=2.1$ case (Figure 24). There is also a slight growth of the low frequency end of the spectrum, as indicated in Figure 25, however it is not as apparent as in the $M=2.5$ case.

The percentage zero crossing decreases in the $M=2.1$ and $M=2.5$ natural jet cases may not seem significant compared to the 30 percent decrease over a $25 \mathrm{~m}$ range experienced by Webster and Blackstock (2). 
However, if we assume that the zero crossing decreases are due only to atmospheric attenuation (which preferentially attenuates the higher frequencies), we would expect to find a greater percentage of zero crossing decreases in the lower Reynolds number experiments where the absorption is much higher. This is not the case. Hence, the relatively significant decrease in zero crossings (when compared to the lower Reynolds number cases) and the increase in the lower frequency part of the spectrum suggest that true nonlinear propagation effects have been observed at moderate Reynolds numbers. 


\section{CHAPTER V}

\section{SUMMARY AND CONCLUSIONS}

The major results of this study support the hypothesis that nonlinear propagation effects occur in high speed jet noise. In this study the noise from low and moderate Reynolds number jets was measured at varying locations along the maximum noise emission path of the jets. The signals were recorded on a magnetic tape recorder and then later digitized. The propagation time delay of the noise signal between the microphones was calculated and the signals were time shifted accordingly. A digital Fast Fourier Transform (FFT) of the time shifted microphone signals enabled an accurate spectral analysis to be performed.

The major characteristics of nonlinear propagation were outlined in the introduction of this thesis. The first characteristic was steepen ing of the propagating waveshape. In an effort to quantify this phenomenon, a wave steepening factor (WSF) was defined. This factor was found to fairly accurately determine the relative amount of wave steepening (and the harmonic growth associated with this). A comparison of microphone signals from low Reynolds number excited jets showed that significant wave steepening occurred. A spectral analysis of the same microphone signals clearly indicated an increase in the higher frequency content of the spectrum, another characteristic of nonlinear propagation. Some evidence of low frequency production was also found in the $M=2.5$ 
low Reynolds number unexcited jet.

The moderate Reynolds number jets showed a significant decrease in zero crossings and a considerable increase in the low frequency portion of the normalized spectra, Although there is not conclusive evidence that this low frequency growth was due solely to shock merging, the indications are that at least part, if not all, of the zero crossing decreases were due to this phenomenon (for reasons discussed earlier).

To further understand the effect of nonlinear propagation in jet noise, more work is needed in the following areas:

1. Experiments at intermediate Reynolds numbers between those used in this study, need to be undertaken to determine the effect Reynolds number plays on the distance required for shock formation.

2. A lengthening of the facility is needed to provide a longer propagation distance for the noise signals.

3. A comparison of predicted and measured waveforms using the measured waveform close to the jet as input to available computer codes (10, $11,18)$ would prove enlightening. 
(1) Burns, S. H., "Generation and Propagation of Finite-Amplitude, Rounded, Inverted Sawtooth Waves in Air," J. Acoust. Soc. Am. 45 (1), 1969.

(2) Webster, D. A., and D. T. Blackstock, "Experimental Investigation of Outdoor Propagation of Finite Amplitude Noise," NASA Contractor Report NASA CR-2992.

(3) Webster, D. A., and D. T. Blackstock, "Finite-Amplitude Saturation of Plane Sound Waves in Air," J. Acoust, Soc. Am. 62 (3), 1977.

(4) Lockwood, J. C., T. G., Moore and D. T. Blackstock, "Directive Harmonic Generation in the Radiation Field of a Circular Piston," J. Acoust. Soc. Am. 53 (4), 1973.

(5) Pernet, D. F. and R. C. Payne, "Non-Linear Propagation of Signals in Air," J. Sound Vib. 17 (3), 1971.

(6) Thuras, A. L., R. T. Jenkins and H. T. O'Neil, "Extraneous Frequencies Generated in Air Carrying Intense Sound Waves," J. Acoust. Soc. Am. $\underline{6}, 1935$.

(7) Allen, C. H., "Finite Amplitude Distortion in a Spherically Diverging Sound Wave in Air," Ph.D. Dissertation, Penn. State Co1lege, Dept. of Physics, 1950.

(8) Campanella, A. J., "Acoustic Wave Propagation Distortion at Several Frequencies," M.S. Thesis, Penn. State College, Dept. of Physics, 1953.

(9) Campanella, A. J., "Finite Amplitude Distortion of Spherically Diverging Intense Sound Waves in Air," J. Acoust. Soc. Am. 67 (1), Jan. 1980.

(10) Blackstock, D. T., "Nonlinear Propagation Distortion of Jet Noise," Proceedings, Third Interagency Symposium on University Research in Transport Noise, University of Utah, Nov. 1975.

(11) Crighton, D. G. , and S. Bashforth, "Nonlinear Propagation of Broadband Jet Noise," AIAA paper 80-1039, June 1980.

(12) Kenda11, J. M., "Supersonic Boundary Layer Stability Experiments," Proceedings of the Boundary Layer Transition Study Group Meeting, Vo1. II, Aerospace Report No, TR-0158 (53816-63)-1, 1967. 
(13) Morrison, G. L., "Flow Instability and Acoustic Radiation Measurements of Low Reynolds Number Supersonic Jets," Ph.D. Dissertation, Oklahoma State University, 1977.

(14) Johnson, C. B., and L. R. Boney, "A Method of Calculating a Rea1Gas Two-Dimensional Nozzle Contour Including the Effects of Gamma," NASA TM X-3243, Langley Research Center, Hampton, Virginia, 1975.

(15) Rott, N. and L. R. Crabtree, "Simplified Laminar Boundary-Layer Calculations for Bodies of Revolution and For Yawed Wings," J. Aero. Sci. 19, 1952.

(16) Morrison, G. L. and D. K. McLaughlin, "Noise Generation by Instabilities in Low Reynolds Number Supersonic Jets," J. Sound Vib. 65, 1979 .

(17) Troutt, T. R., "Measurements on the Flow and Acoustic Properties of a Moderate Reynolds Number Jet," Ph.D. Dissertation, Oklahoma State University, 1978.

(18) Morfey, C. L., and G. P. Howe11, "Nonlinear Propagation of Aircraft Noise in the Atmosphere," AIAA Paper No. 80-1041, June 1980.

(19) Douglas Shields, F., and H. E. Bass, "Atmospheric Absorption of High Frequency Noise and Application to Fractiona1-Octave Bands," NASA Contractor Report NASA CR 2760.

(20) Bruel and Kjaer, Quarter-Inch Condenser Microphones, June 1969, p. 16 . 
APPENDIX A

FIGURES 

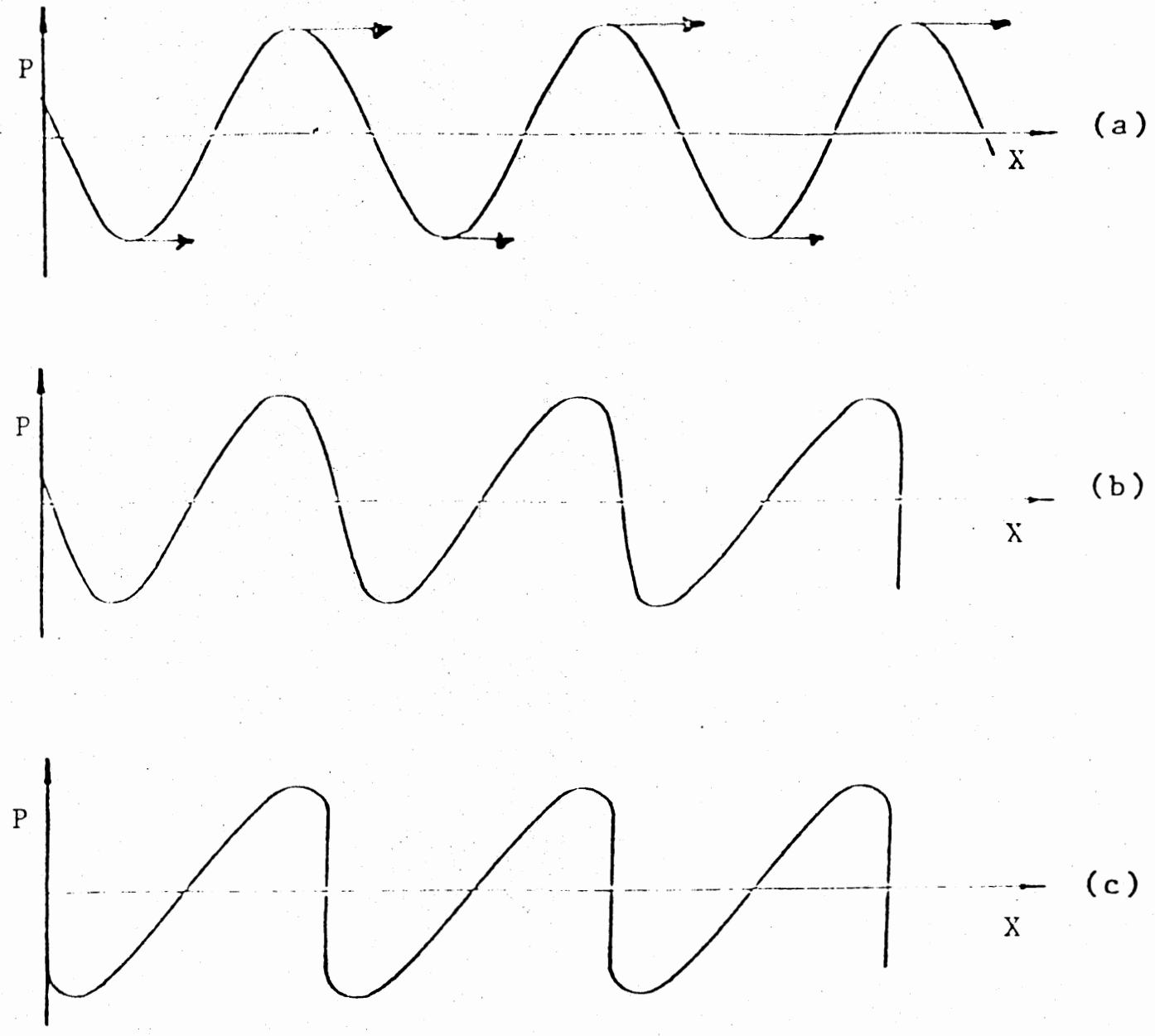

Figure 1. The Effect of Nonlinear Propagation on a Sinusoidal Sound Wave 


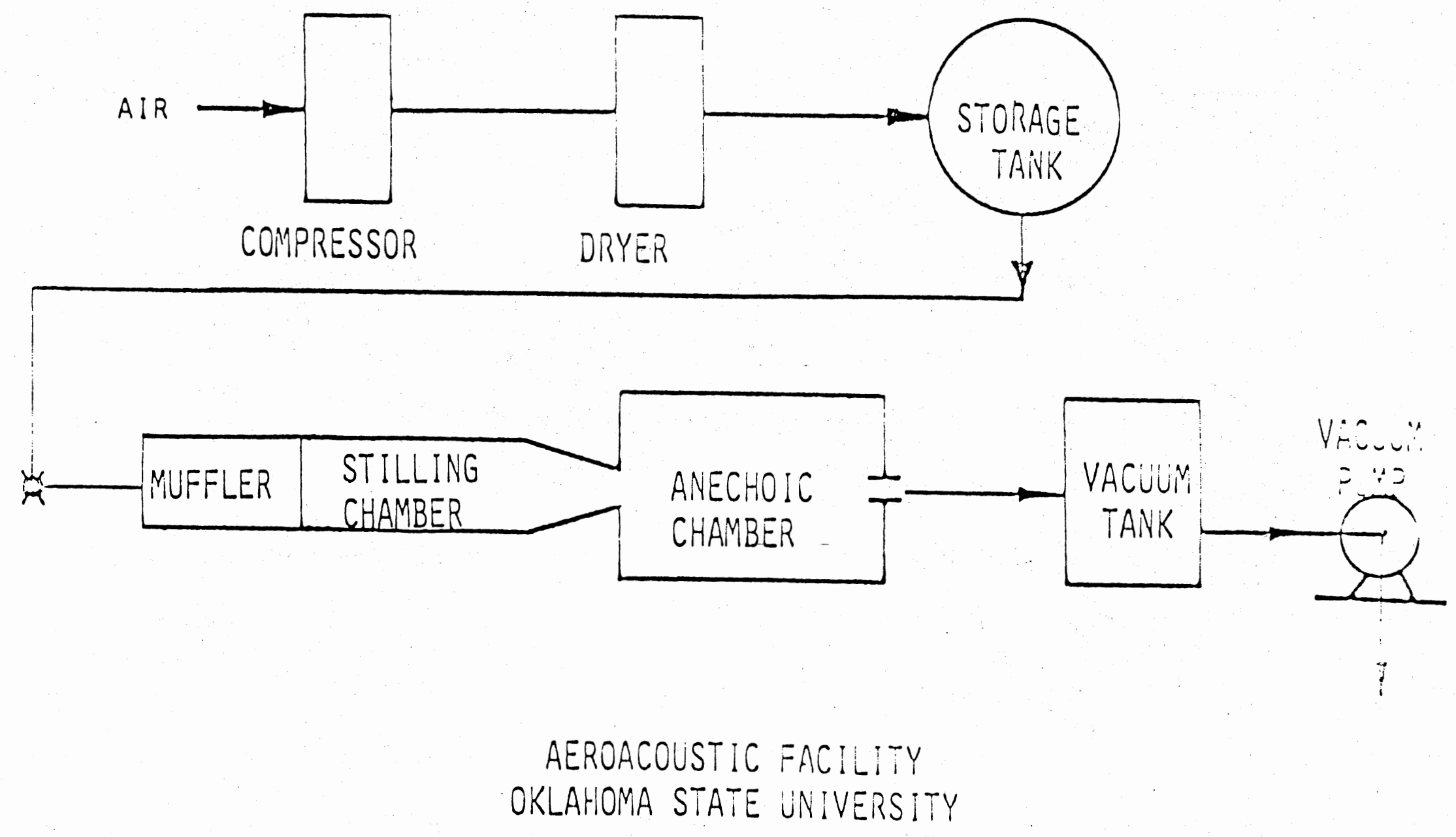

Figure 2. Schematic of Overall Facility 


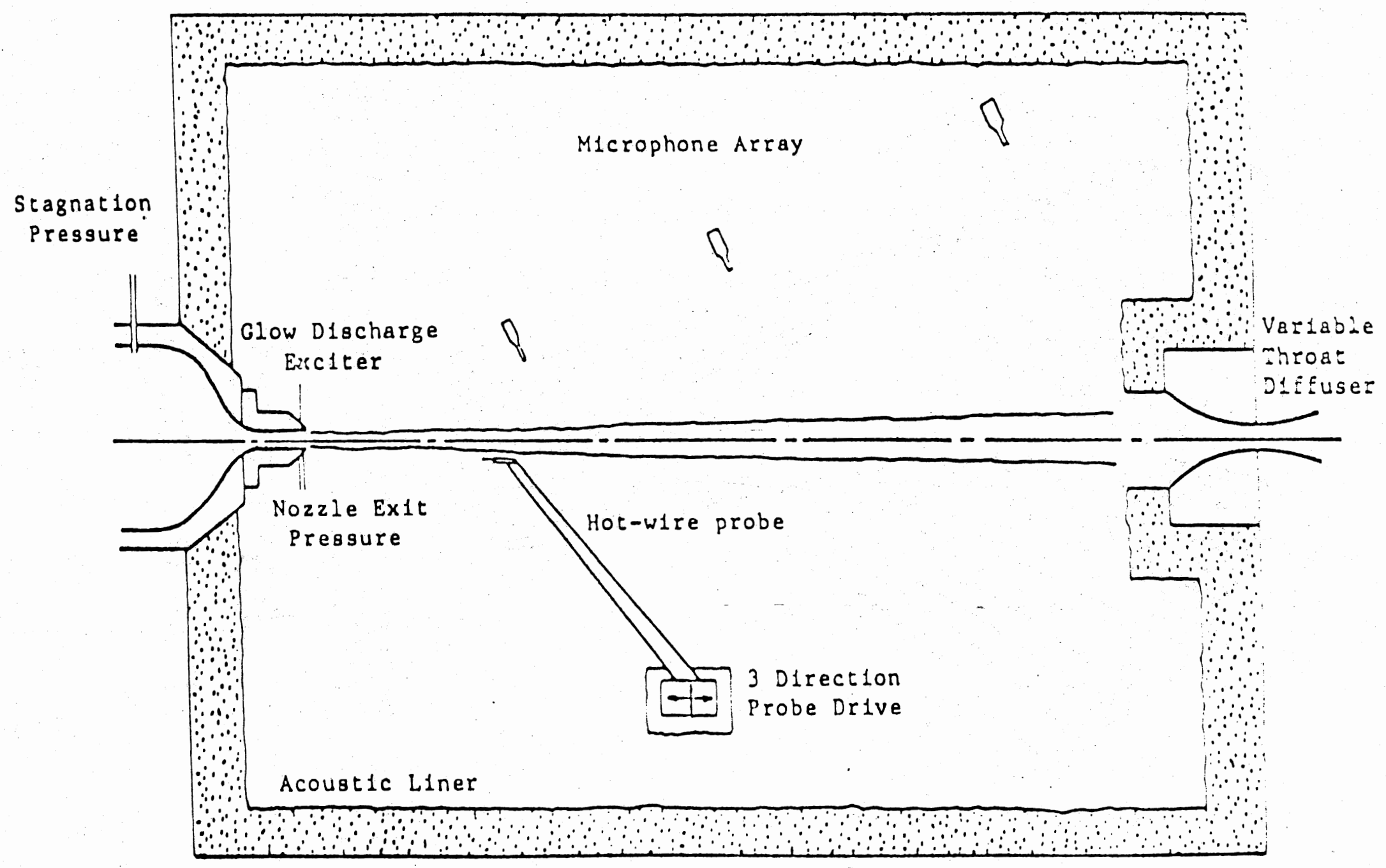

Figure 3. Schematic of Jet Test Facility 


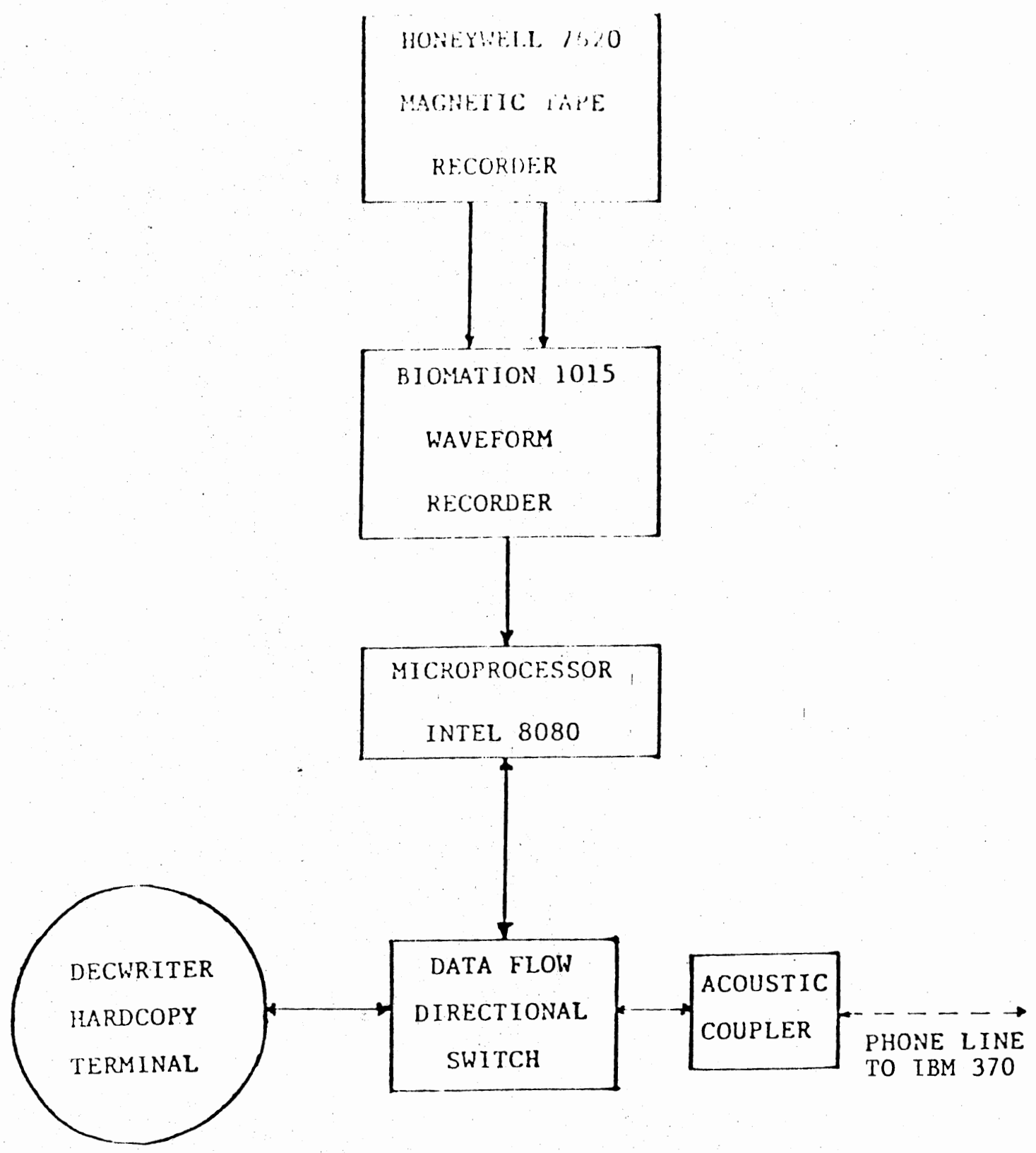

Figure 4. Electronic Arrangement for Digitization 


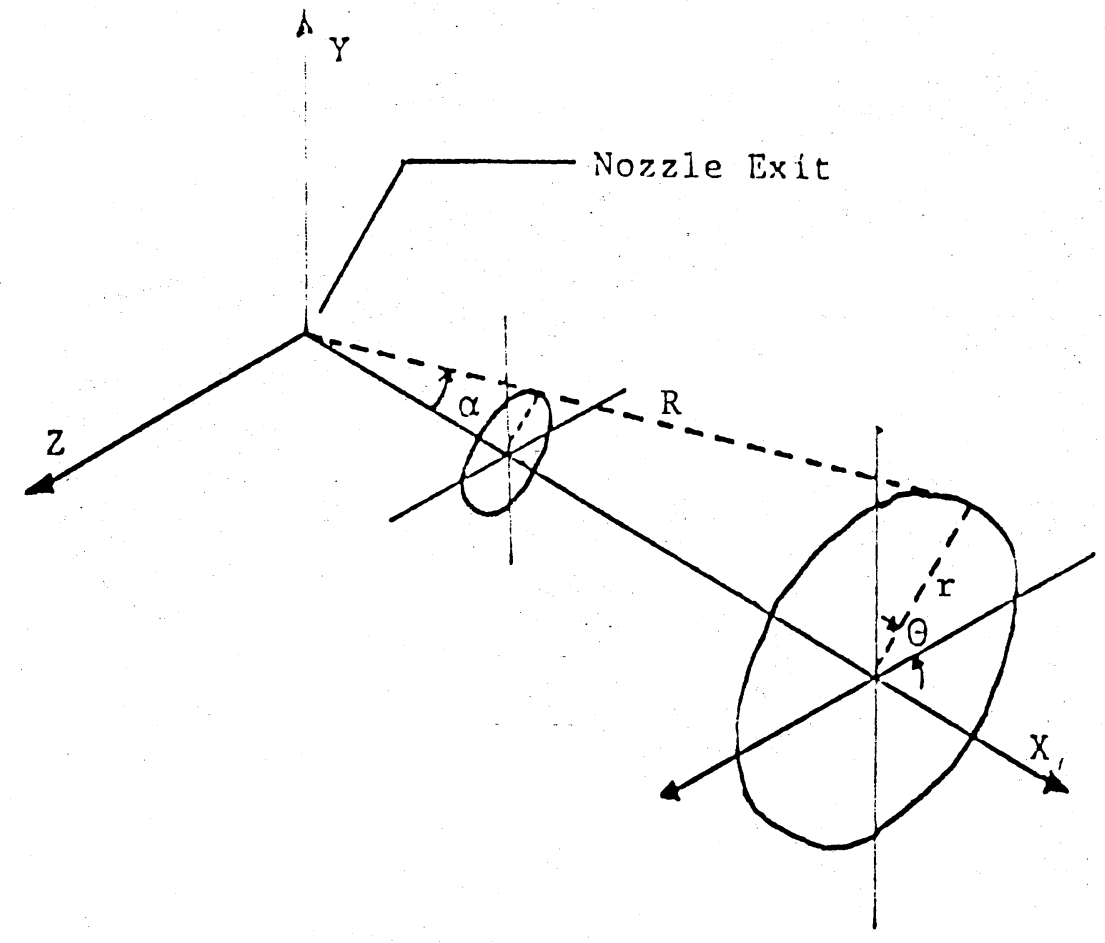

Figure 5. Coordinate Systems Diagram 


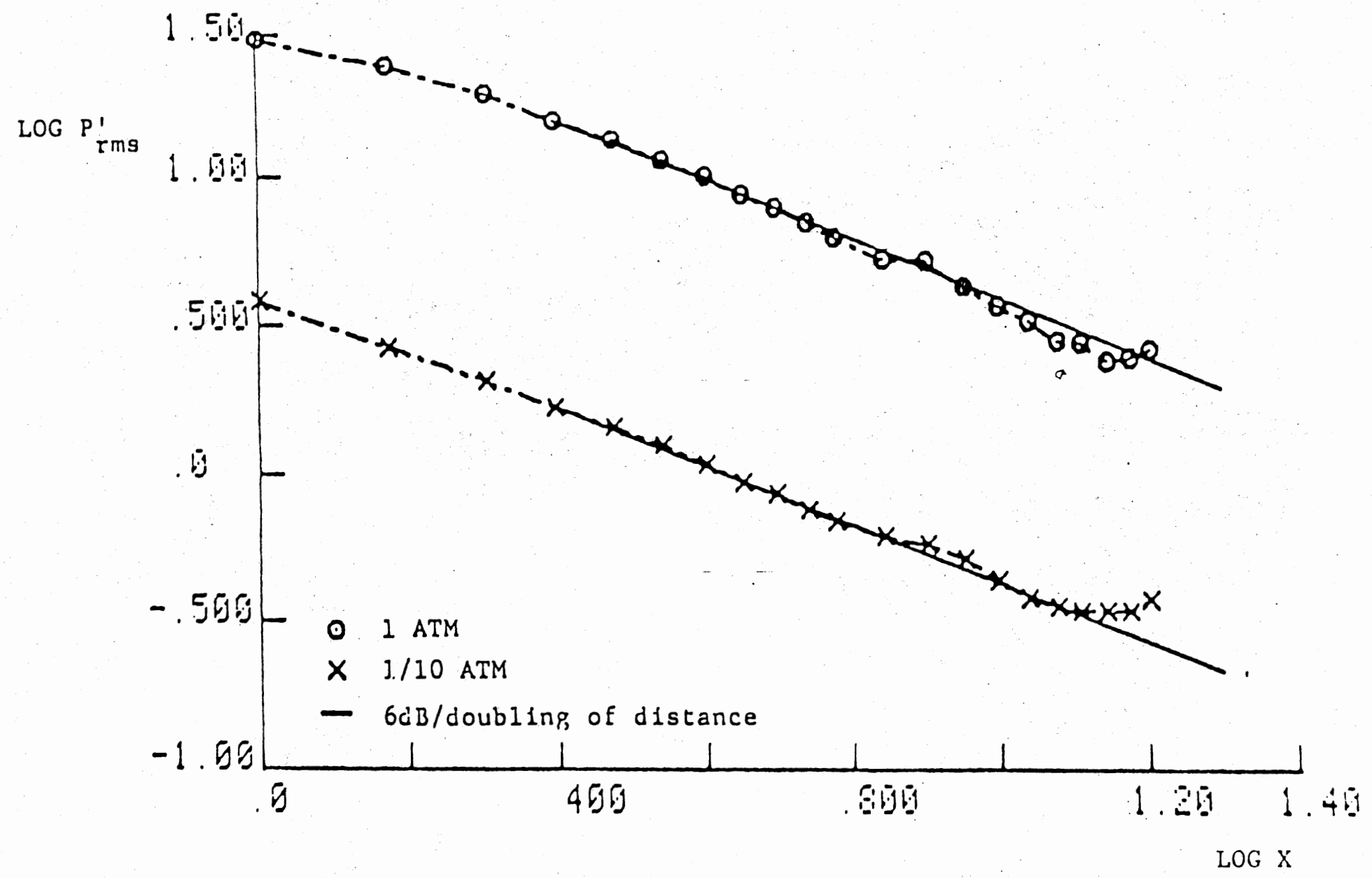

Figure 6. Facility Absorption Calibration Curves. Driver Frequency $=15 \mathrm{KHz}$ 


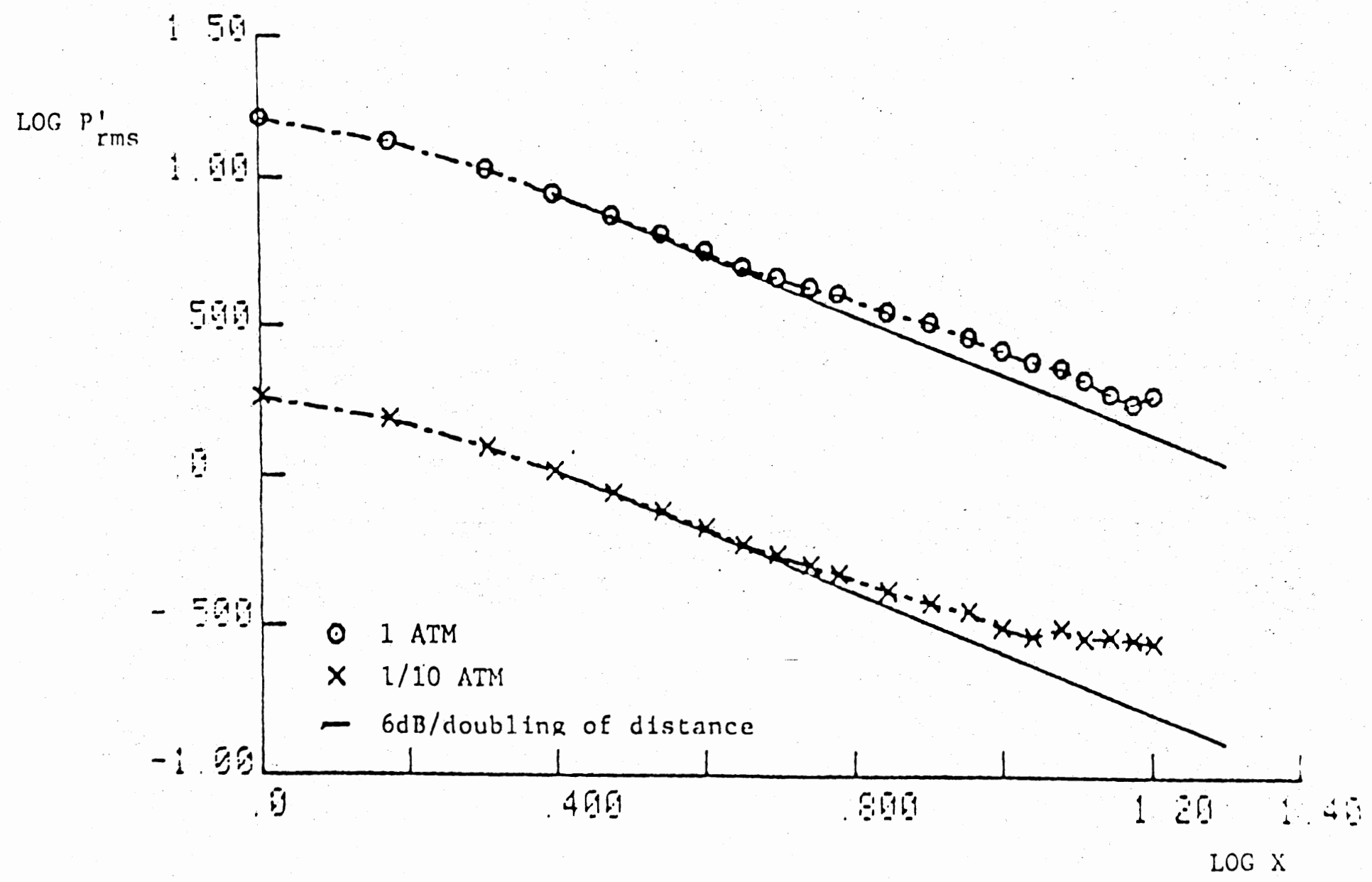

Figure 7. Facility Absorption Calibration Curves. Driver Frequency $=30 \mathrm{KHz}$ 


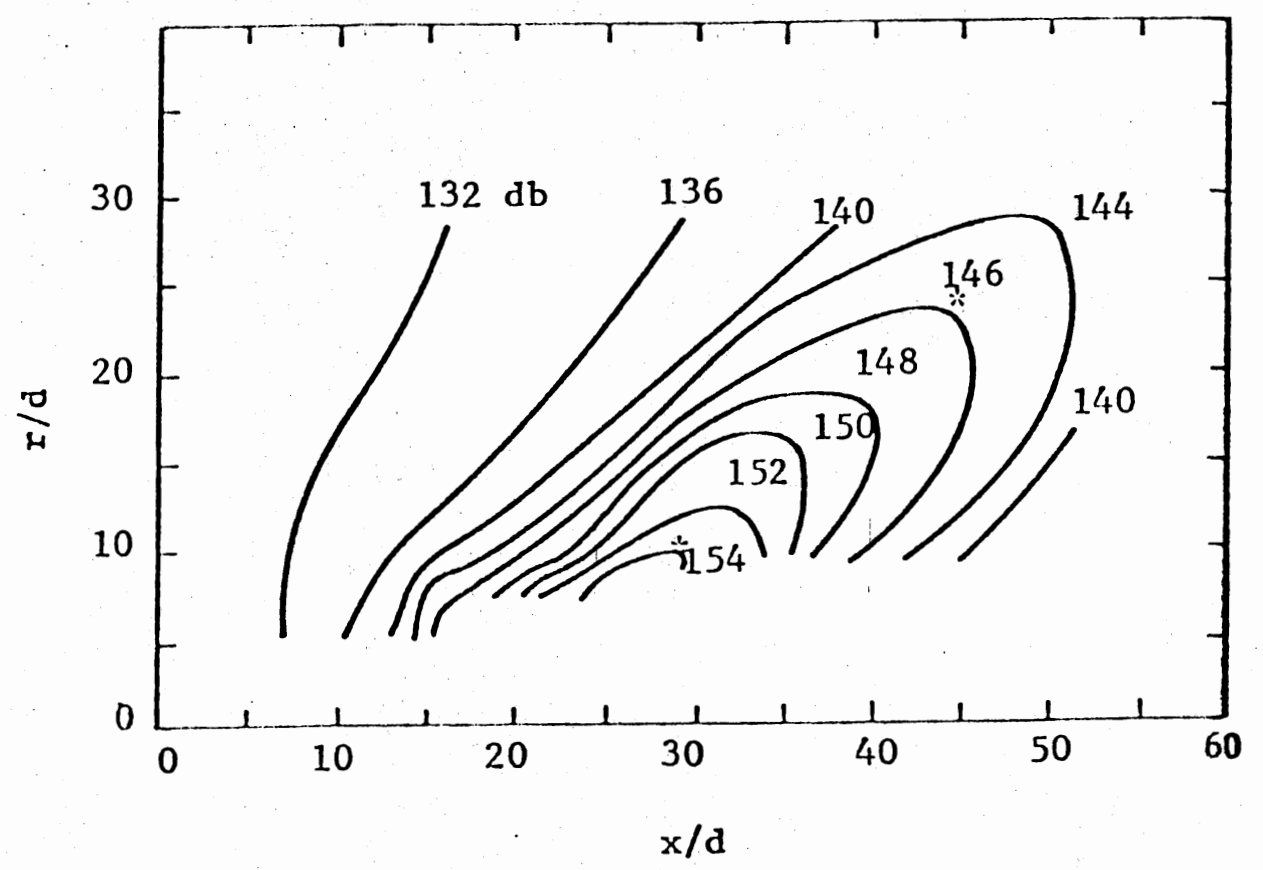

Figure 8. Total Sound Pressure Level Contours of a $M=2.5$ Jet Excited at $\mathrm{St}=0.16 .(*-$ Position of Microphones at $\mathrm{R} / \mathrm{d}=30$ and $\mathrm{R} / \mathrm{d}=50$ ) 


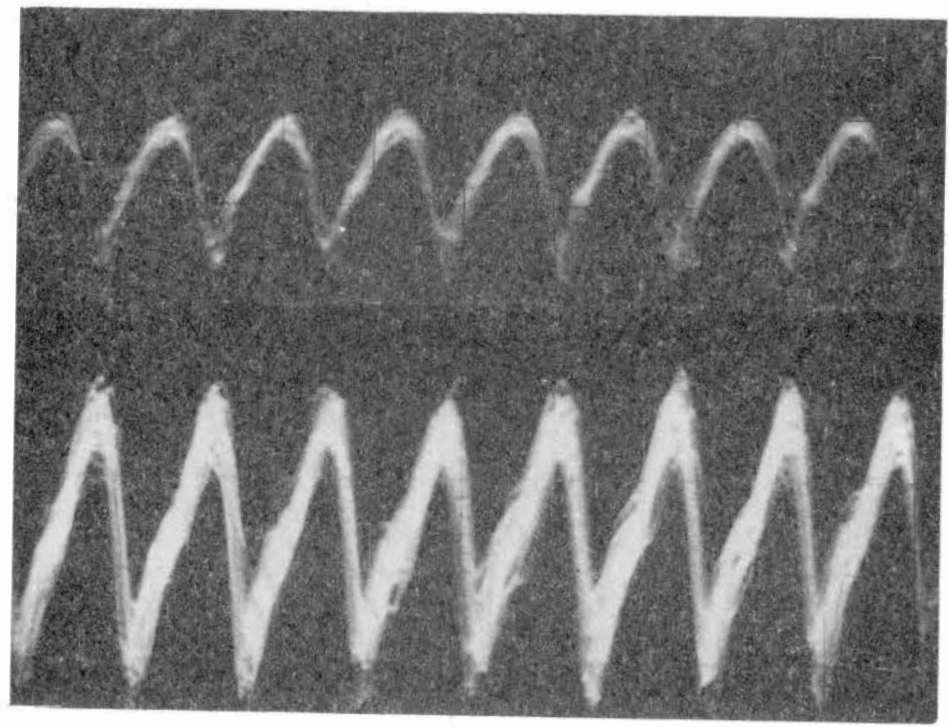

(a)

(b)

Figure 9. Typical Oscilloscope Traces of Microphone Signals at (a) $R / d=30$ (b) $R / d=80$ from a $M=2.5$ Low Reynolds Number Jet Excited at $\mathrm{St}=0.16$ 

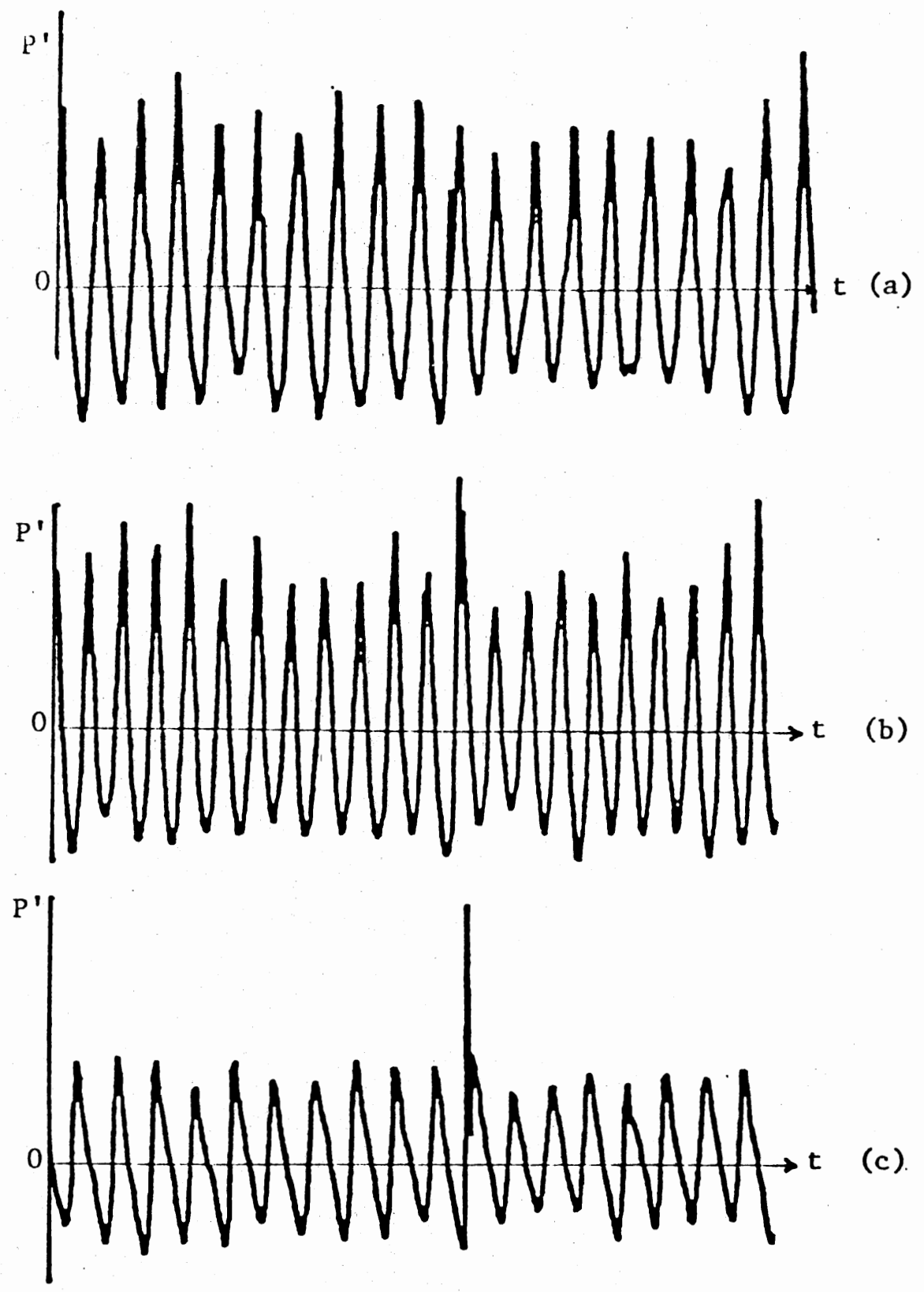

$$
\begin{aligned}
& \text { Figure 10. Waveforms Measured at (a) } \mathrm{R} / \mathrm{d}=30 \text { (b) } \\
& \mathrm{R} / \mathrm{d}=50(\mathrm{c}) \mathrm{R} / \mathrm{d}=80 \text { from } \mathrm{a} M=2.5 \\
& \text { Jet Excited at } \mathrm{St}=0.16(\mathrm{Re}=8,700)
\end{aligned}
$$



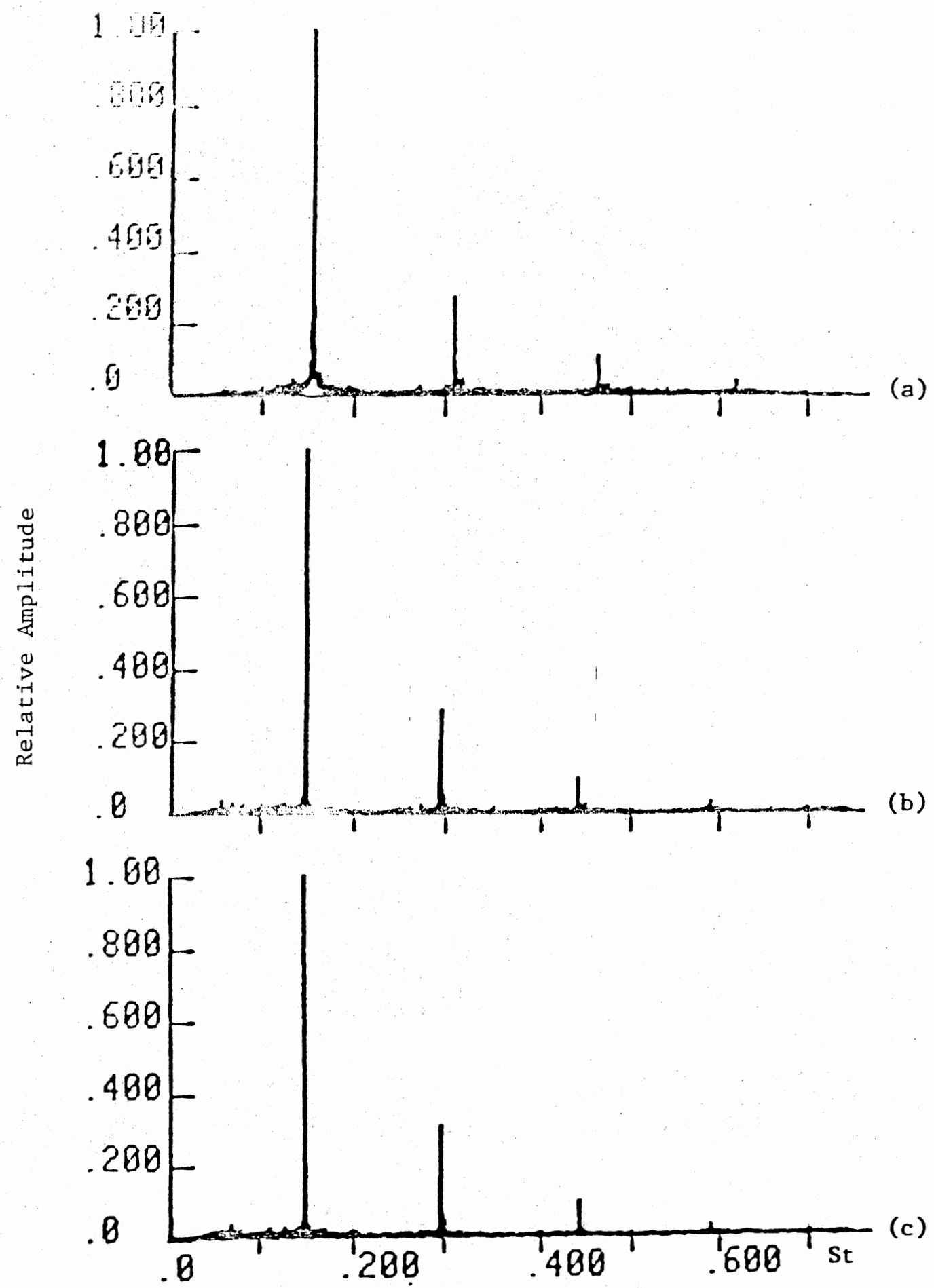

Figure 11. Microphone Spectra Measured at (a) $R / d=30$ (b) $R / d=50$ (c) $R / d=80$ from a $M=2.5$ Jet Excited at $\mathrm{St}=0.16(\operatorname{Re}=8,700)$ 

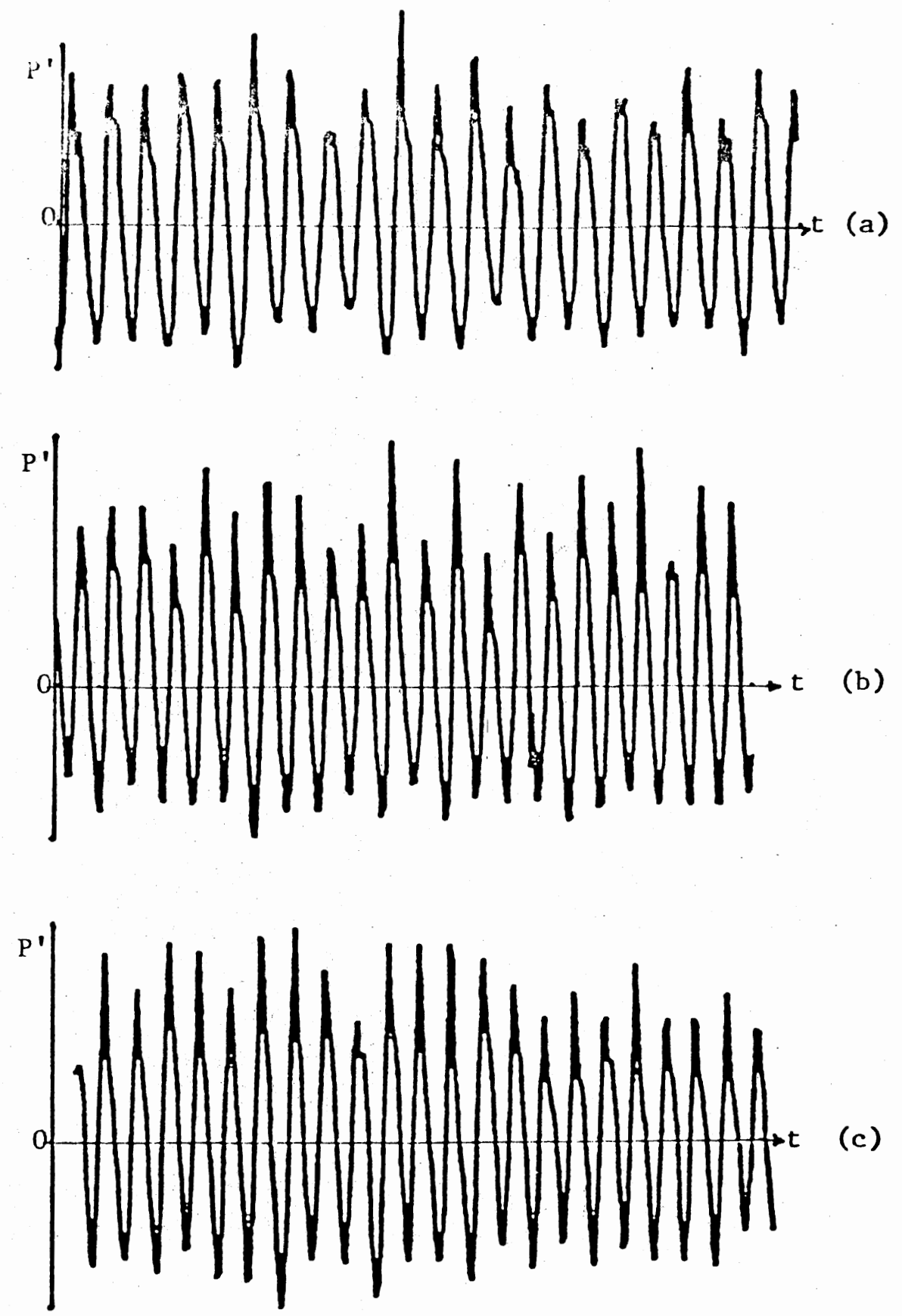

$$
\begin{aligned}
& \text { Figure 12. Waveforms Measured at (a) } \mathrm{R} / \mathrm{d}=30(\mathrm{~b}) \\
& \mathrm{R} / \mathrm{d}=50(\mathrm{c}) \mathrm{R} / \mathrm{d}=80 \mathrm{from} \mathrm{a}=2.1 \\
& \text { Jet Excited at } \mathrm{St}=0.19(\mathrm{Re}=10,000)
\end{aligned}
$$



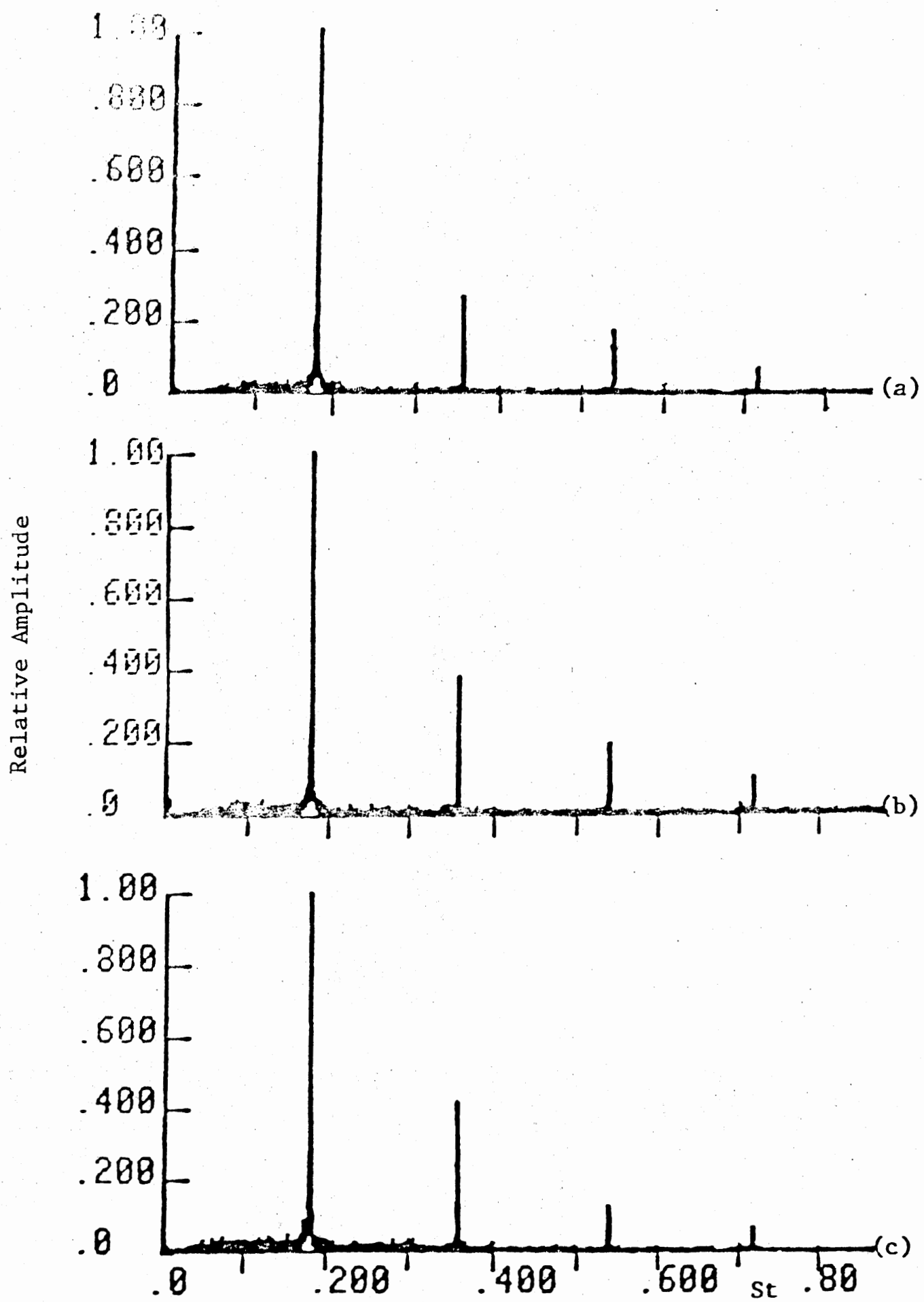

Figure 13. Microphone Spectra Measured at (a) $R / d=30$ (b) $R / d=50$ (c) $R / d=80$, from a $M=2.1$ Jet Excited at $\mathrm{St}=0.19(\operatorname{Re}=10,000)$ 

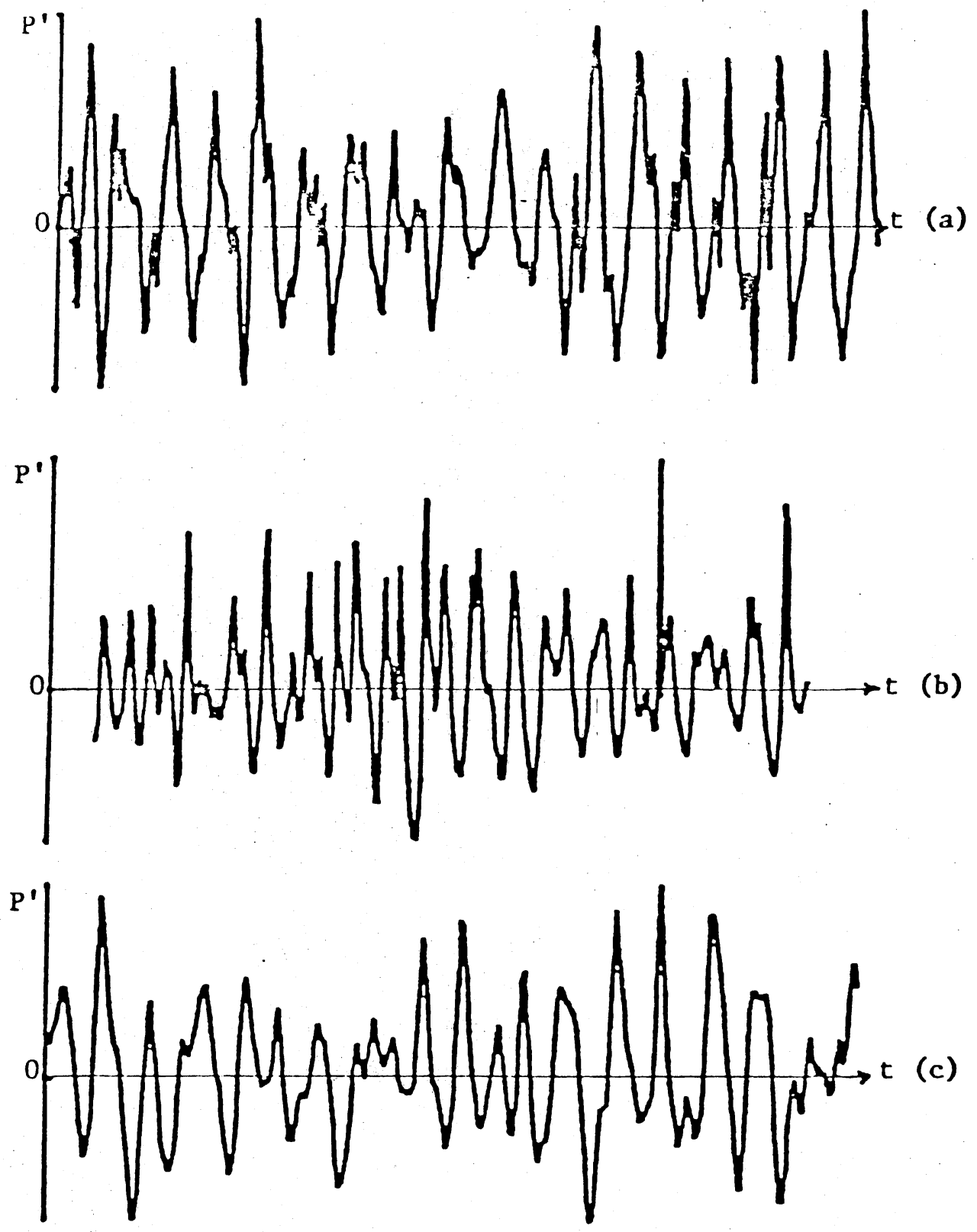

$$
\begin{aligned}
& \text { Figure 14. Waveforms Measured at (a) } R / d=30 \text { (b) } R / d^{2}= \\
& 50 \text { (c) } R / d=80 \text { from a } M=2.5 \mathrm{Jet}(\operatorname{Re}= \\
& 8,700)
\end{aligned}
$$



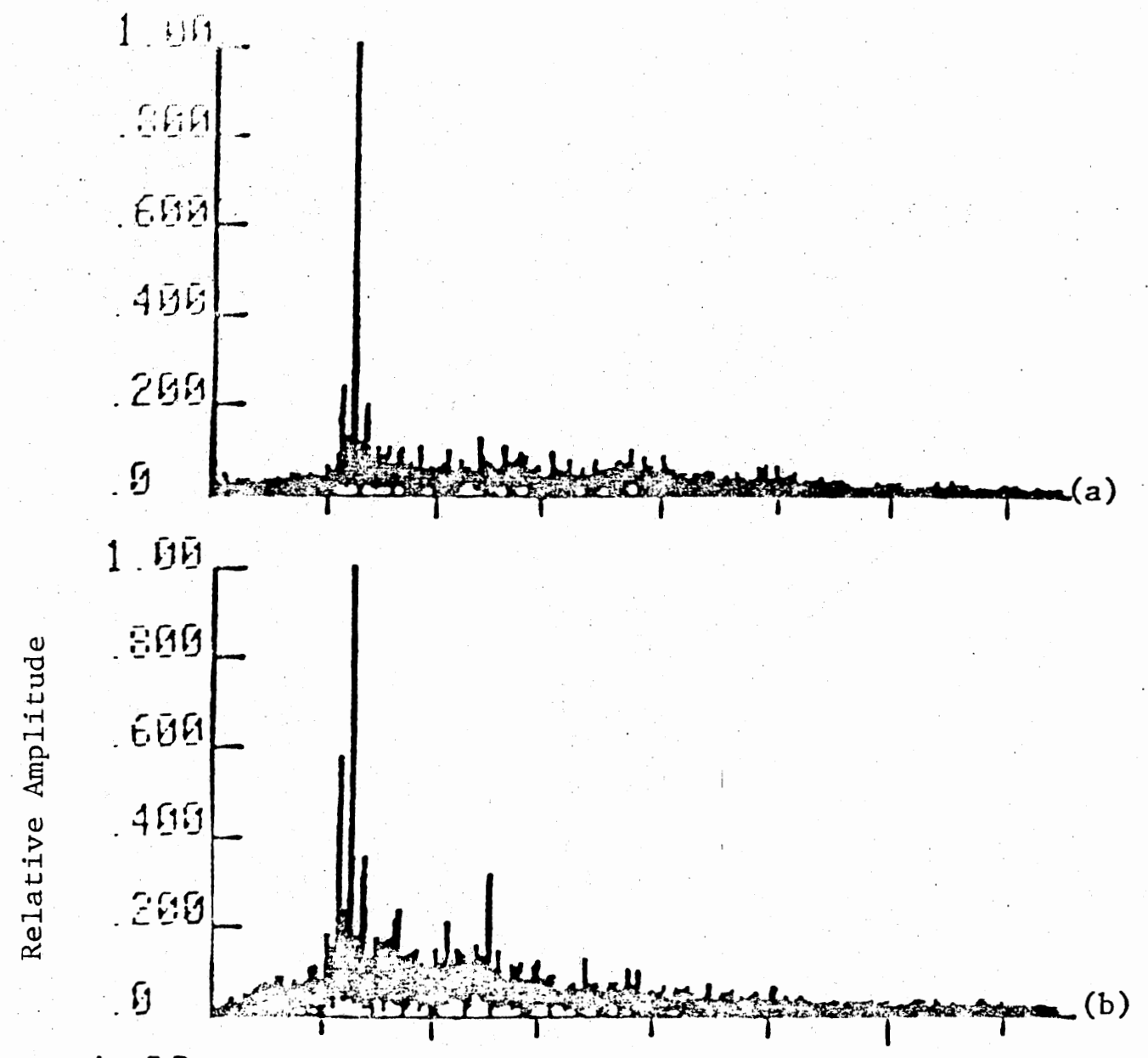

1.00

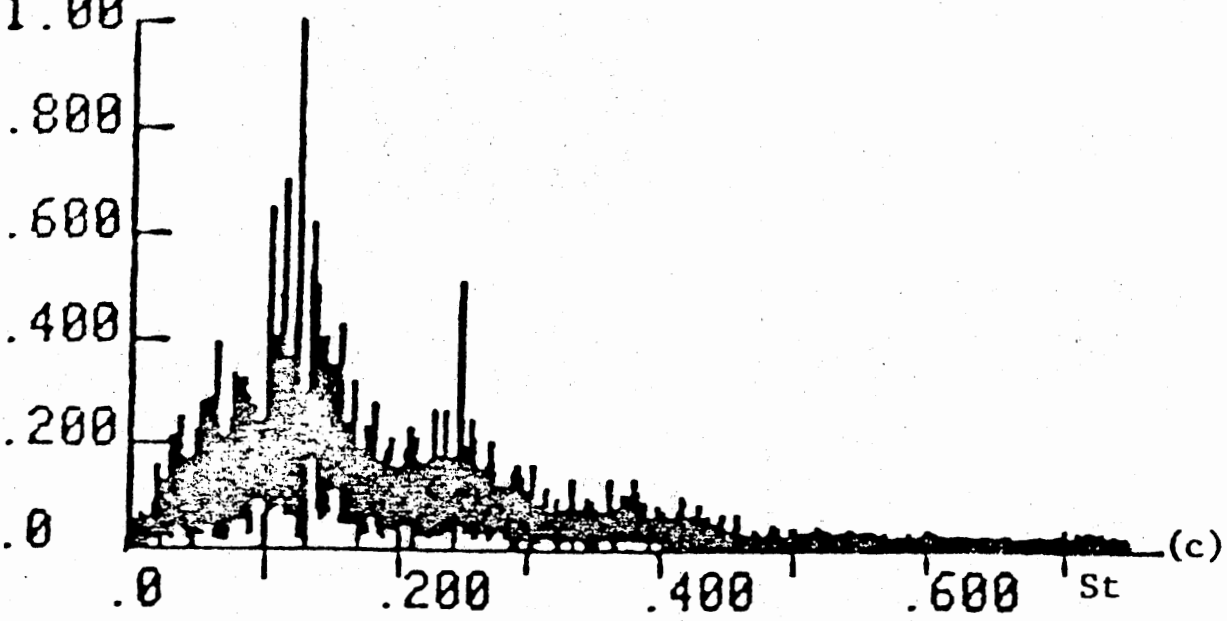

Figure 15. Microphone Spectra Measured at ${ }^{-}$(a) $\mathrm{R} / \mathrm{d}=30$

(c) $R / d=50$ (c) $R / d=80$ from a $M=2.5$ Jet $(\operatorname{Re}=8,700)$ 


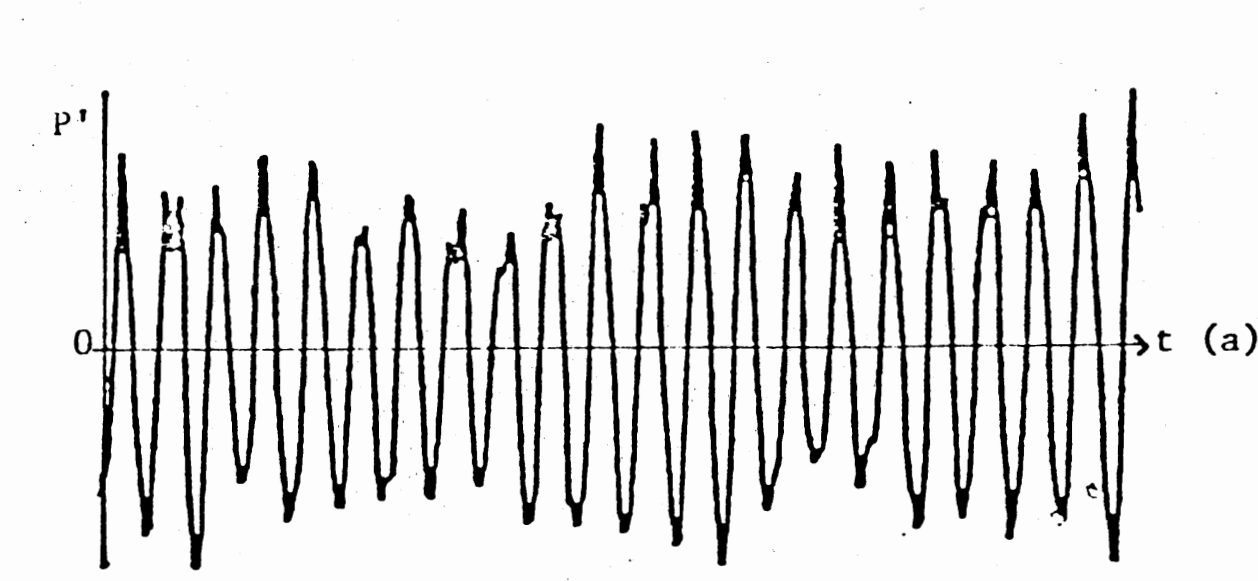

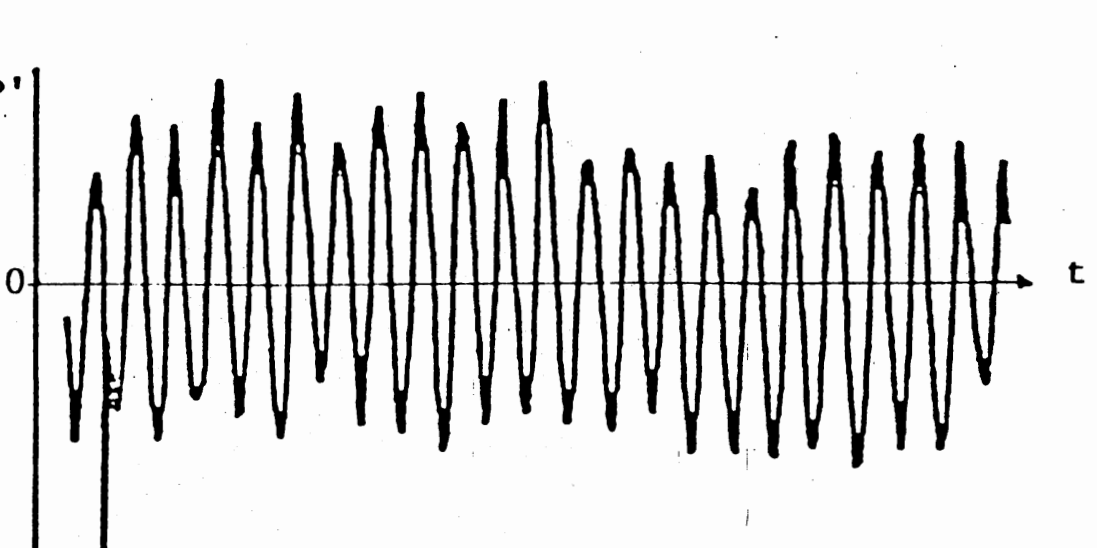

Non 

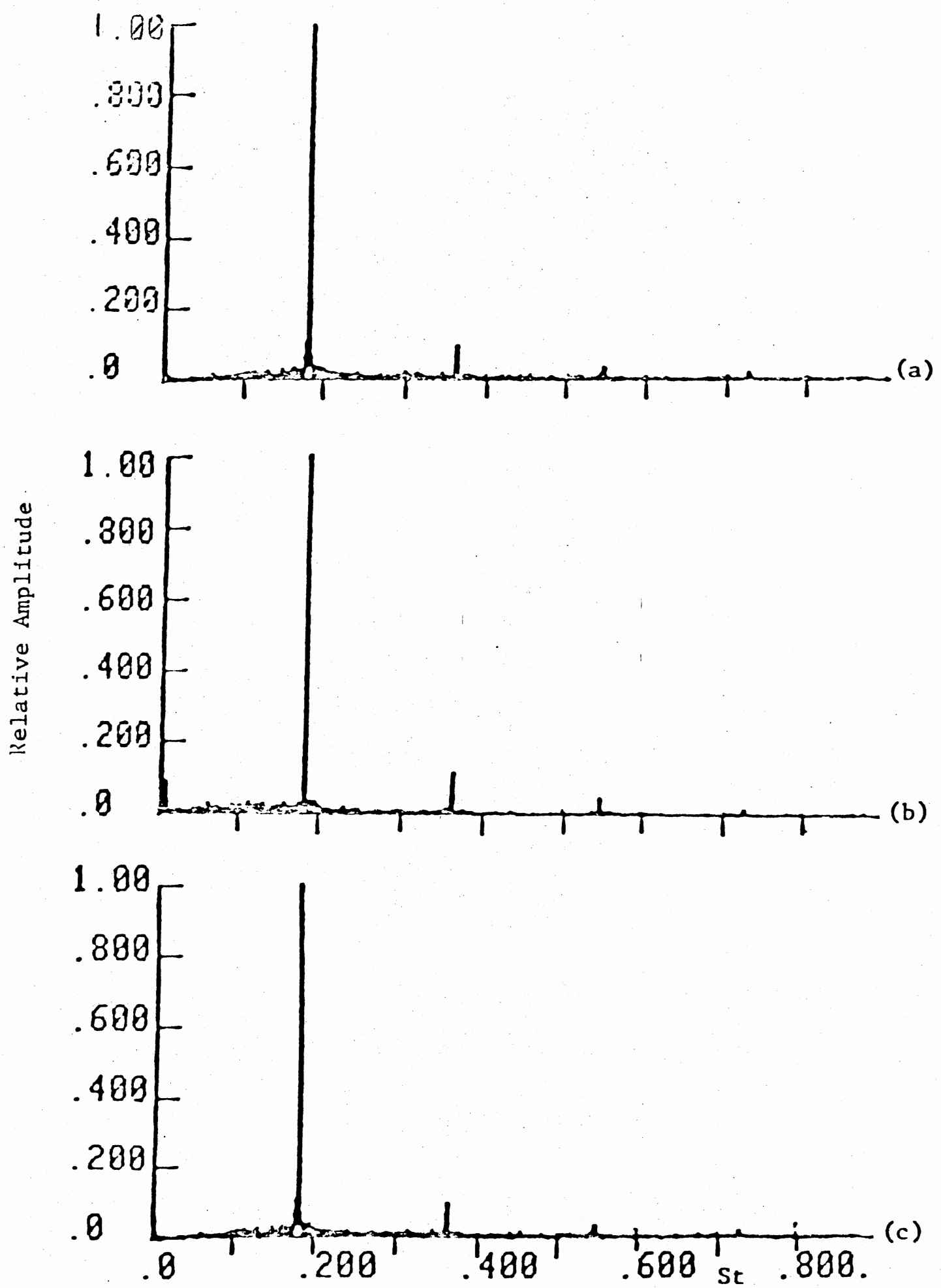

Figure 17. Microphone Spectra Measured at (a) $\mathrm{R} / \mathrm{d}=30$

(b) $\mathrm{R} / \mathrm{d}=50$ (c) $\mathrm{R} / \mathrm{d}=80$ from $\mathrm{a} \mathrm{M}=2.1$

Jet $(\operatorname{Re}=10,000)$ 


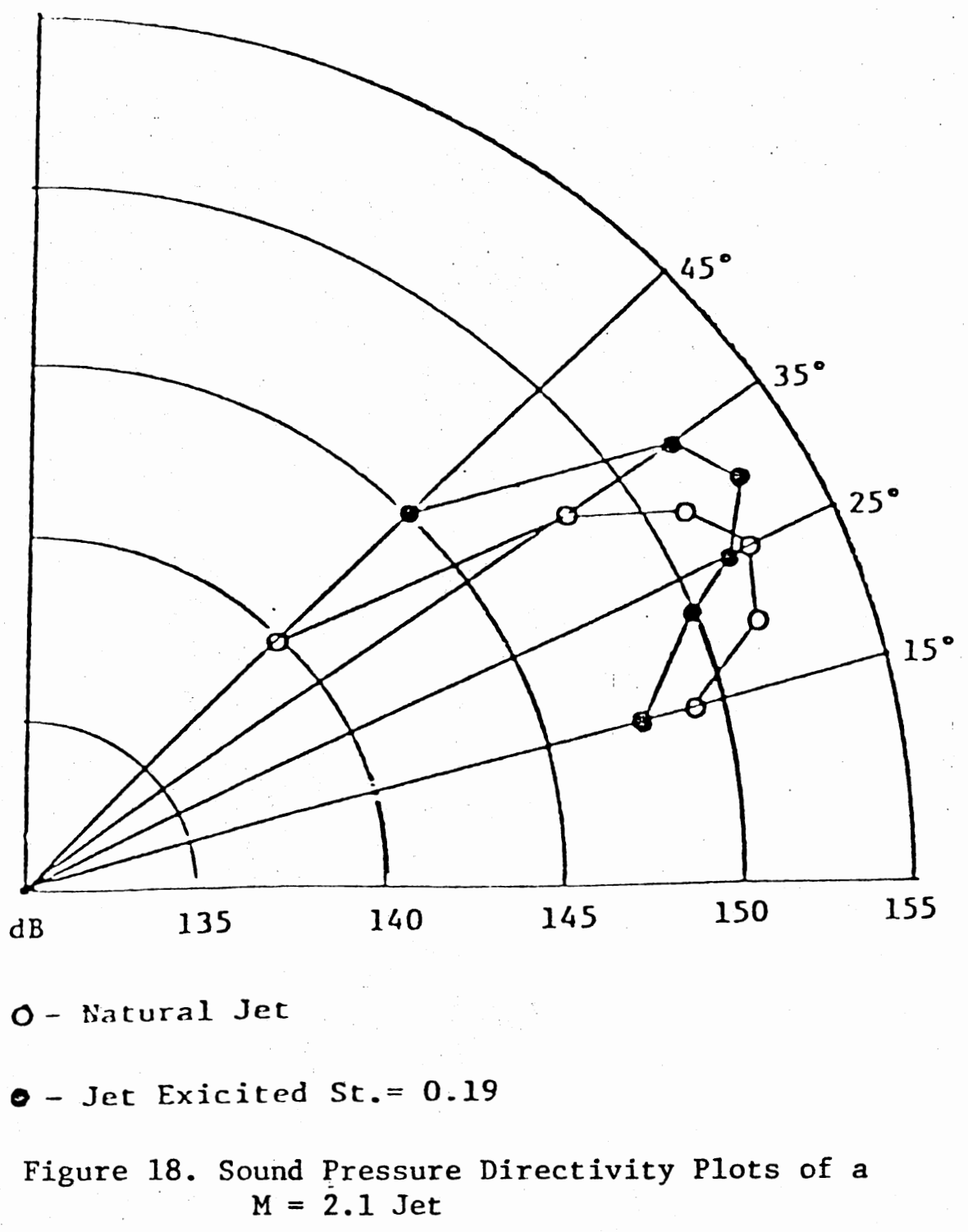



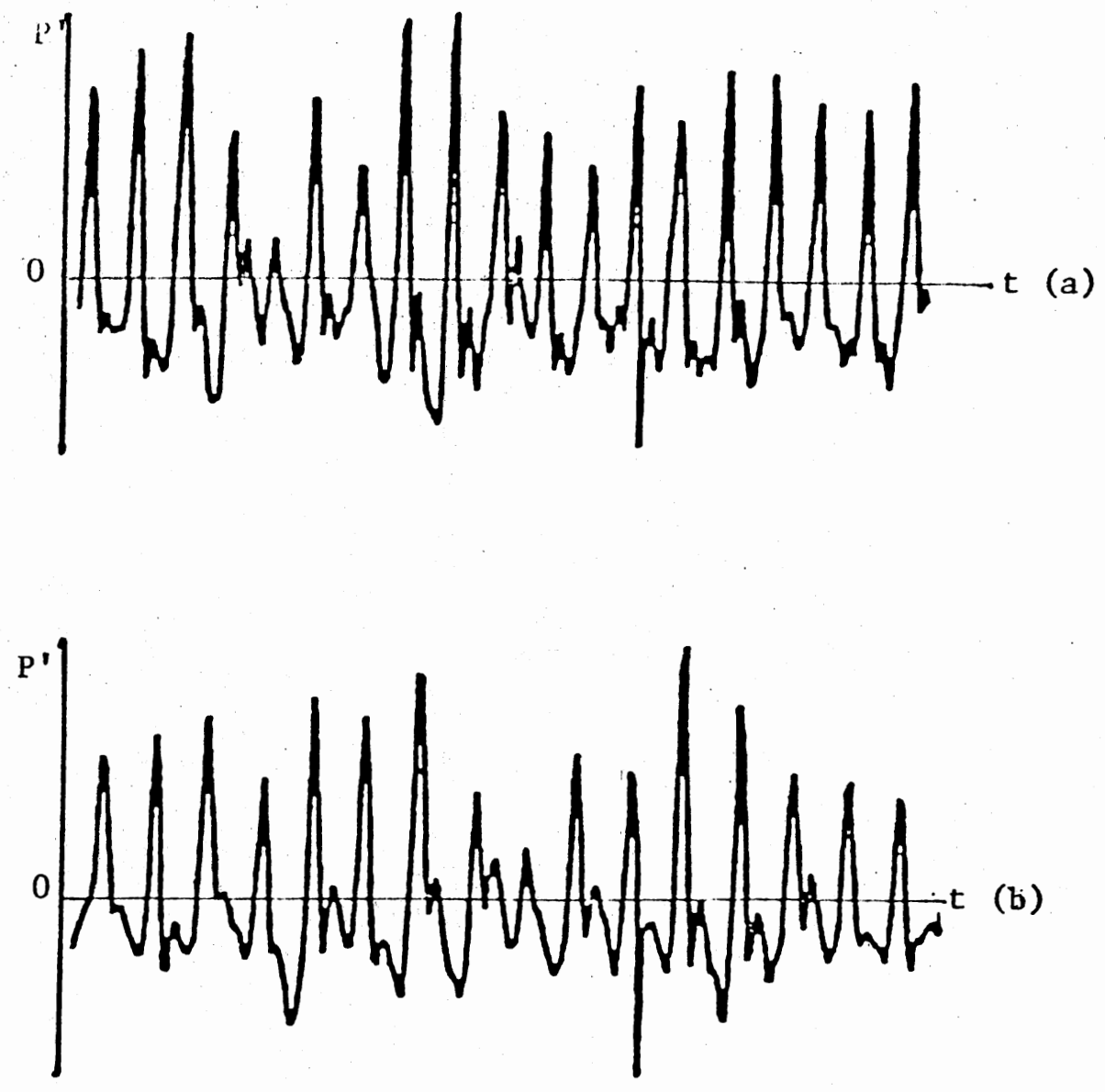

\section{(b)}

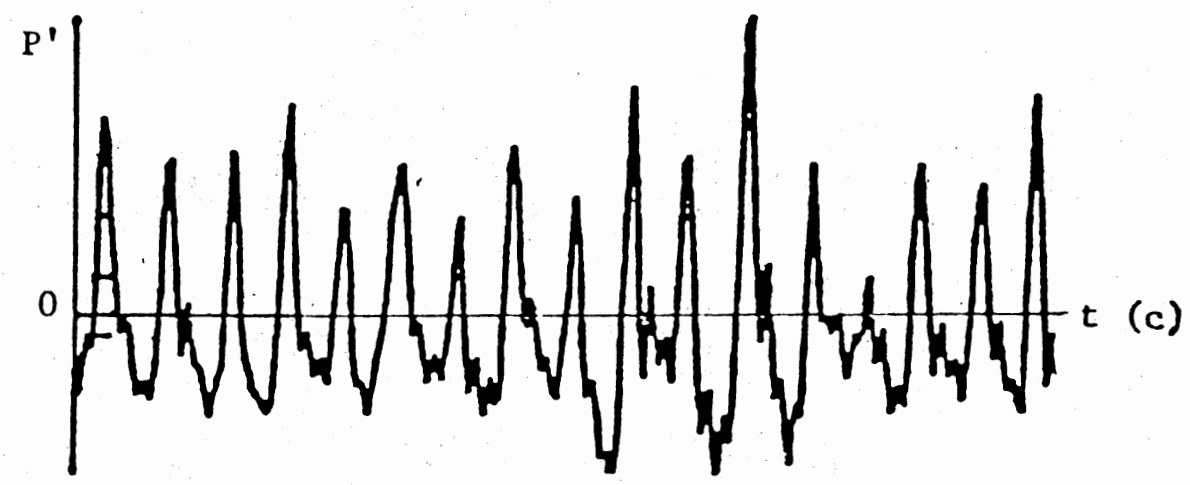
Figure 19. Waveforms Measured at (a) $R / d=30$ (b) $R / d$ $=50$ (c) $\mathrm{R} / \mathrm{d}=80$ from a $\mathrm{ir}=2.5 \mathrm{Jet}$$$
\text { Exciteú at } S t=0.29(\operatorname{Re}=50,000)
$$ 

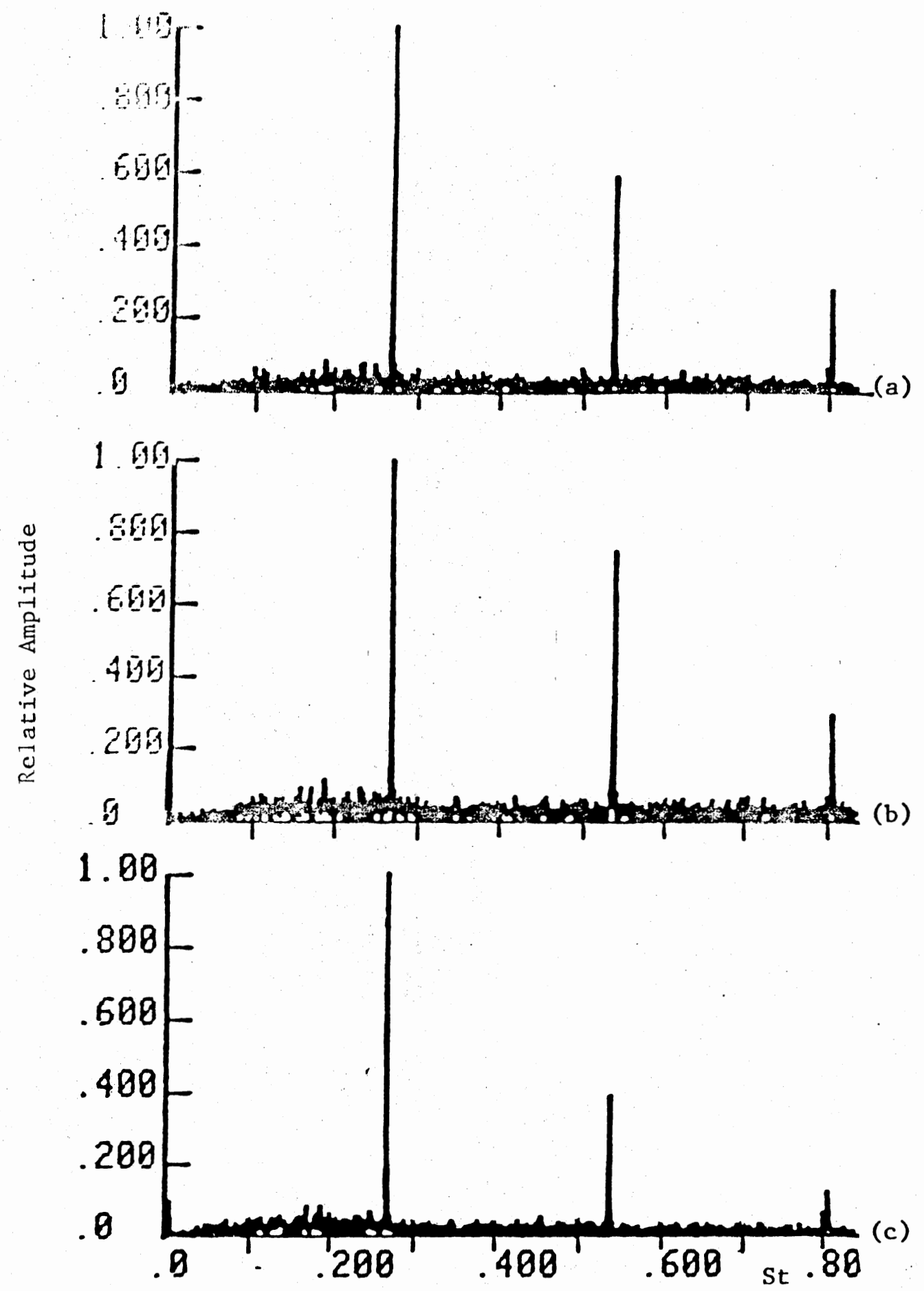

Figure 20. Microphone Spectra Measured at (a) $R / d=30$

(b) $\mathrm{R} / \mathrm{d}=50$ (c) $\mathrm{R} / \mathrm{d}=80$ from $\mathrm{a} \mathrm{M}=2.5$

Jet Excited at St $=0.29(\operatorname{Re}=50,000)$ 
47
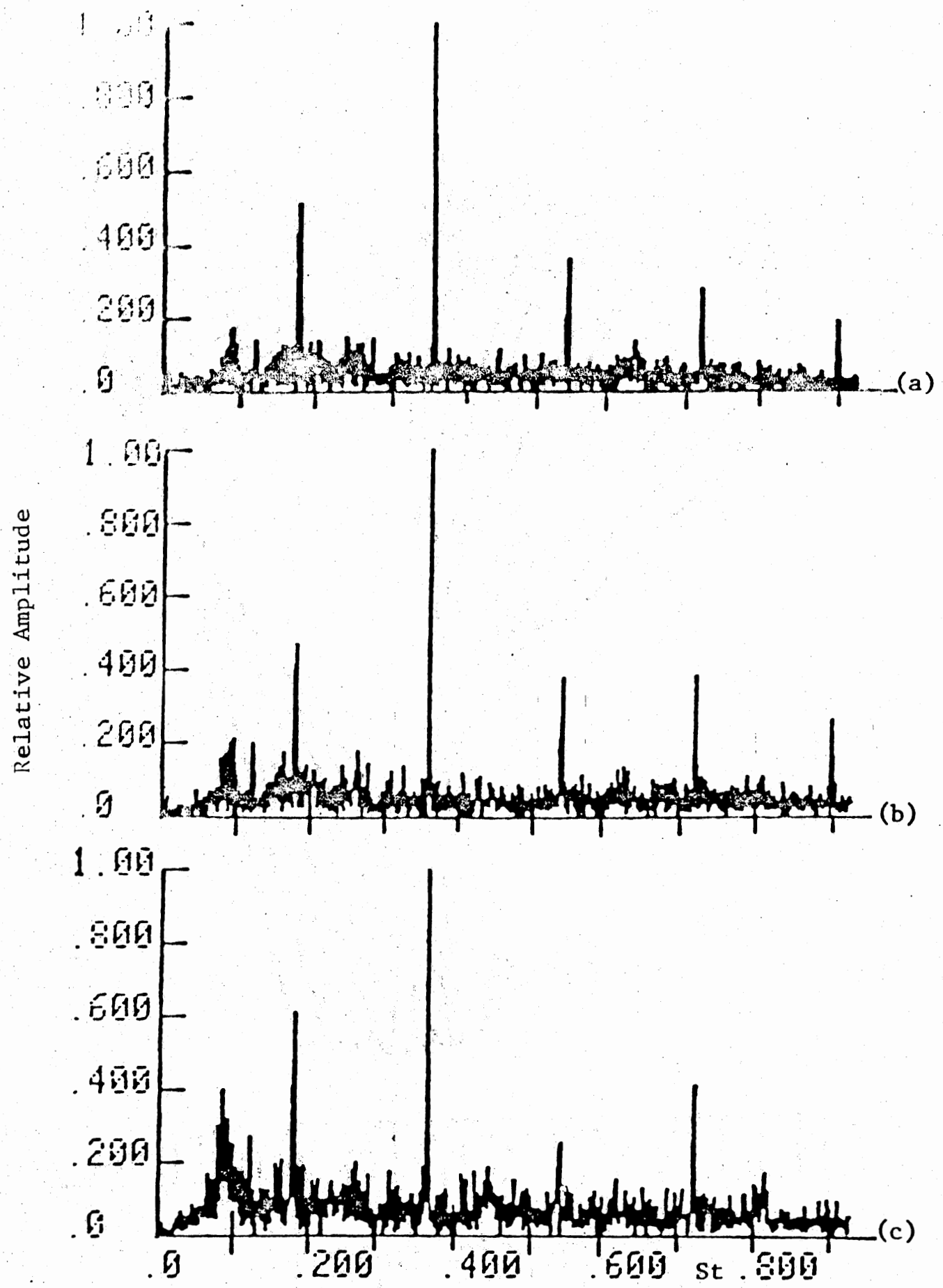

Figure 21. Microphone Spectra measured at (a) $R / d=30$

(b) $R / d=50$ (c) $R / d=80$ from a $M=2.1$

Jet Excited at $\mathrm{St}=0.19(\mathrm{Re}=70,000)$ 

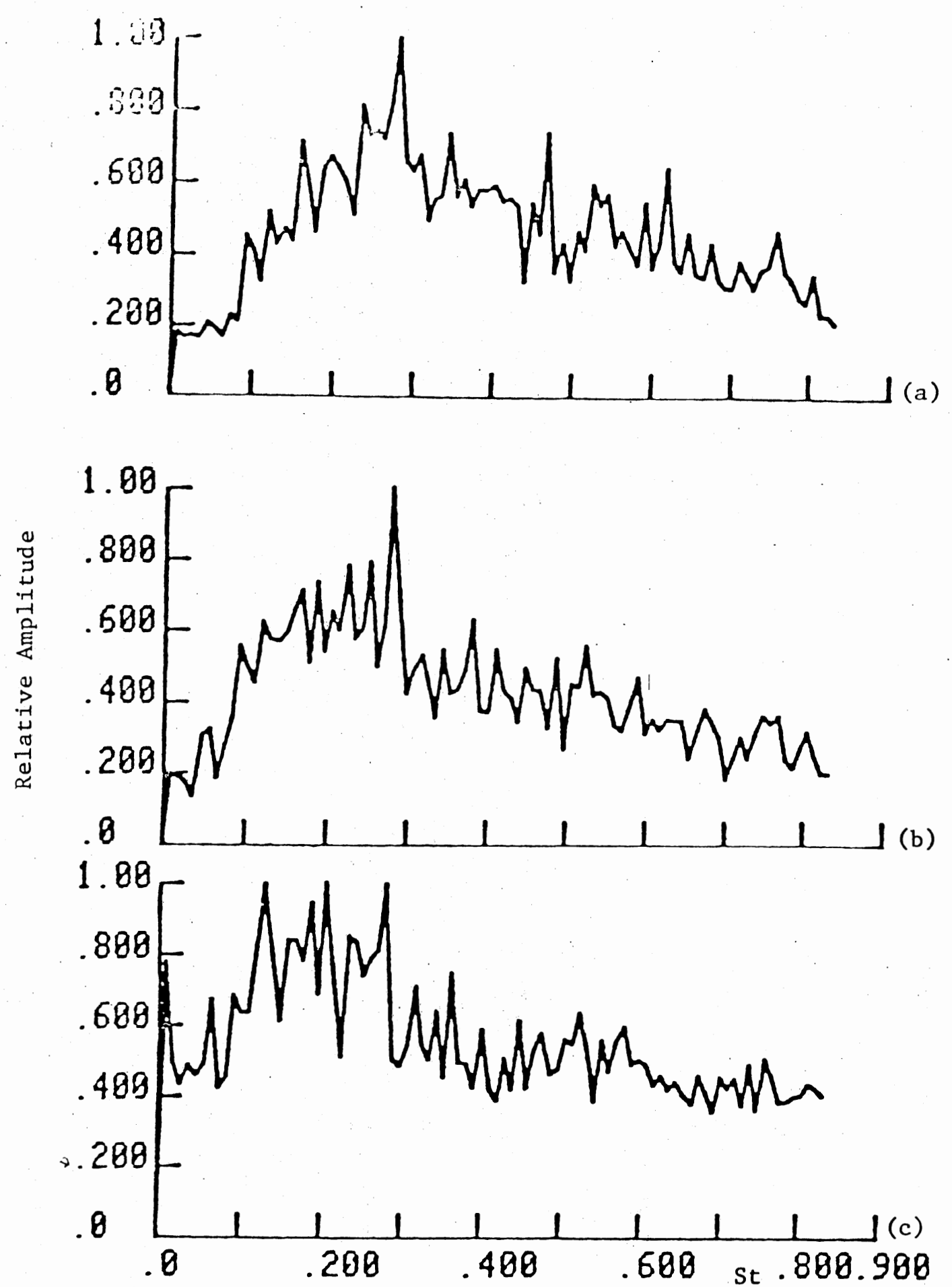

Figure 22. Microphone Spectra Measured at (a) $R / d=30$

(b) $R / d=50$ (c) $R / d=80$, from a $M=2.5$ Jet $(\operatorname{Re}=50,000)$ 

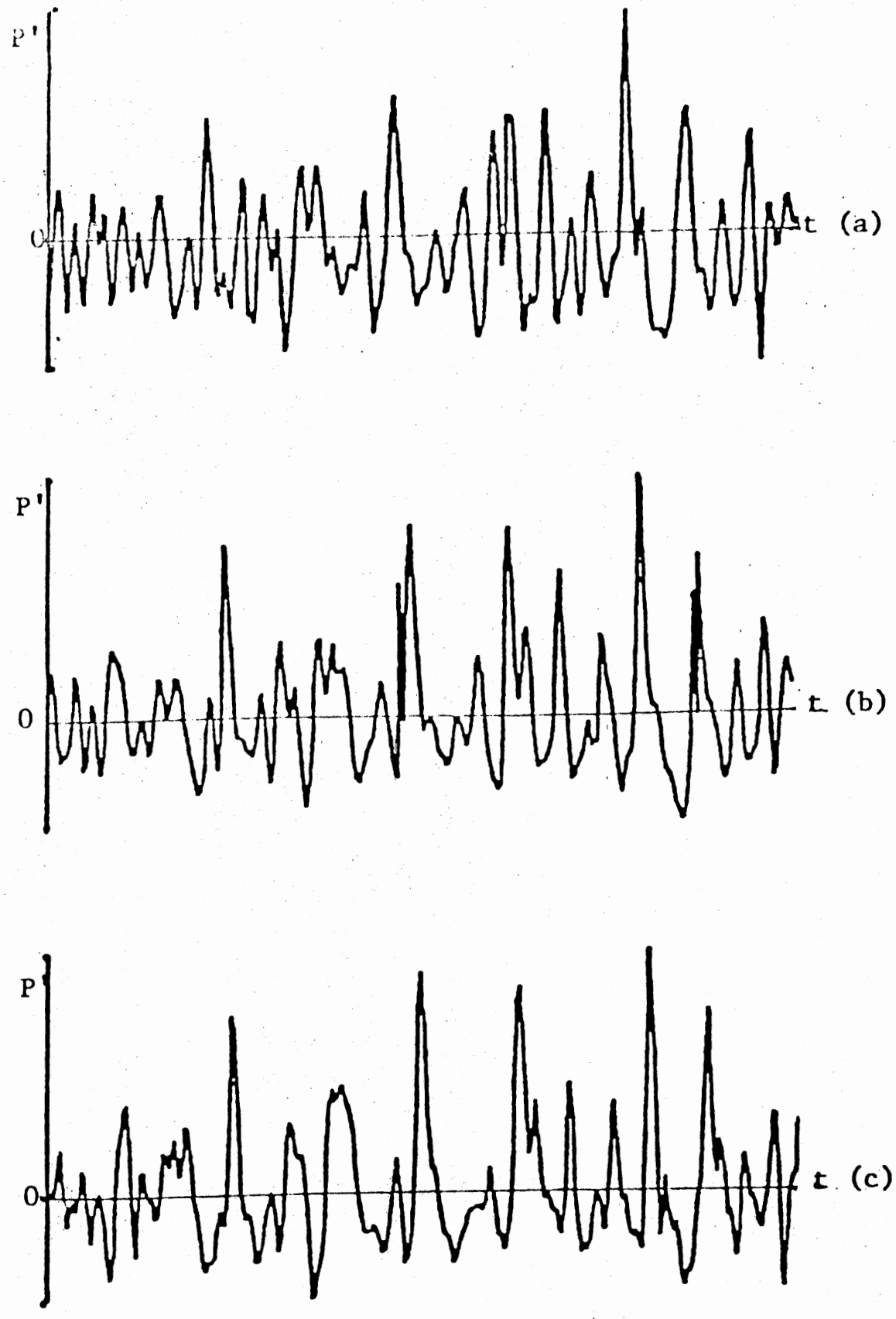

$$
\begin{aligned}
& \text { Figure 23. Waveforms Measured at (a) } R / d=30 \\
& \text { (b) R/d }=50(\text { (c) } R / d=80 \text { from } a \\
& M=2.5 \mathrm{Jet}(\operatorname{Re}=50,000)
\end{aligned}
$$



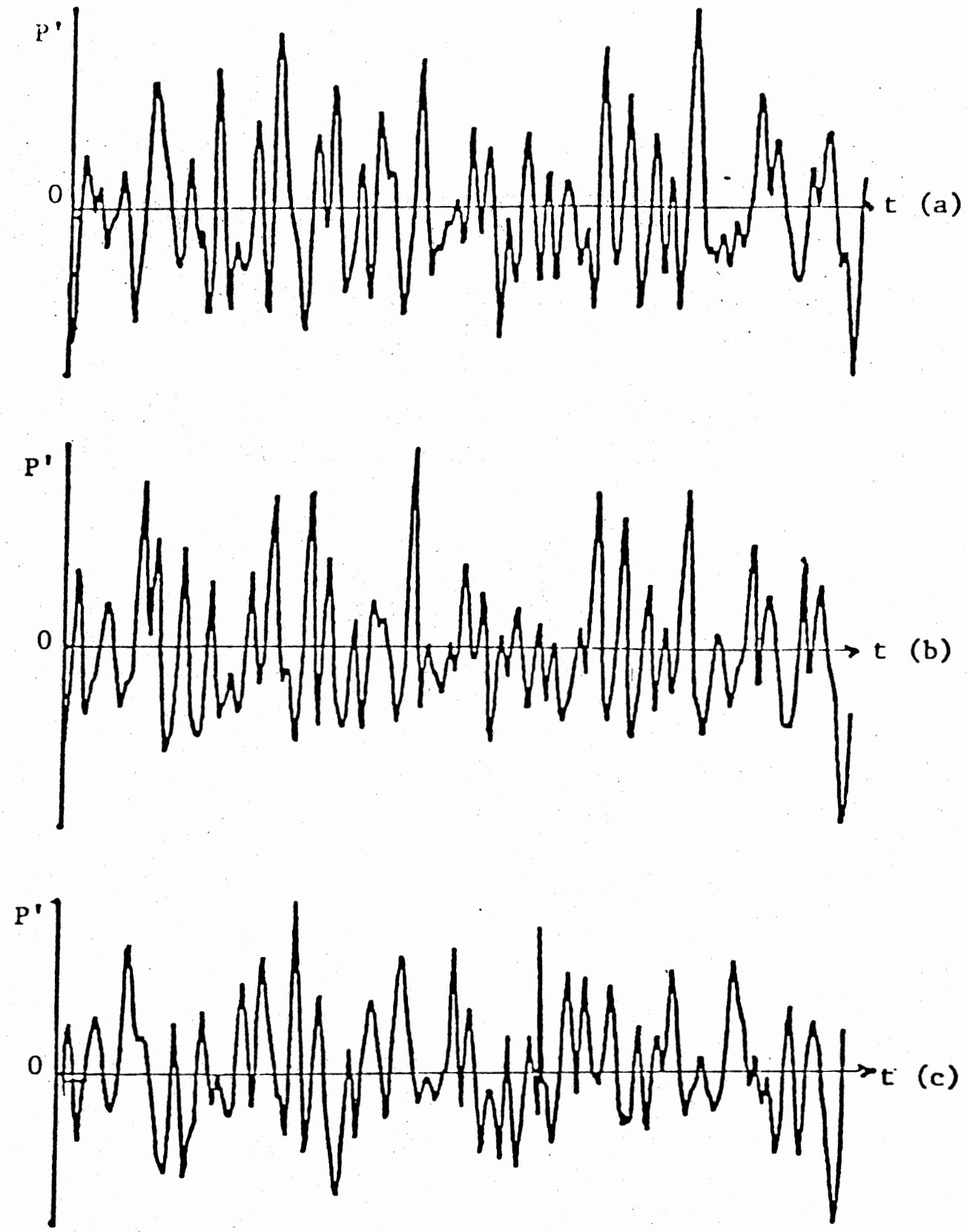

Figure 24. Waveforms Measured at (a) $R / d=30$ (b) $R / d=$
\[ \begin{array}{l}50 \text { (c) } R / d=80 \text { from a } M=2.1 \mathrm{Jet}(\mathrm{Re}= \\ 70,000)\end{array} \] 

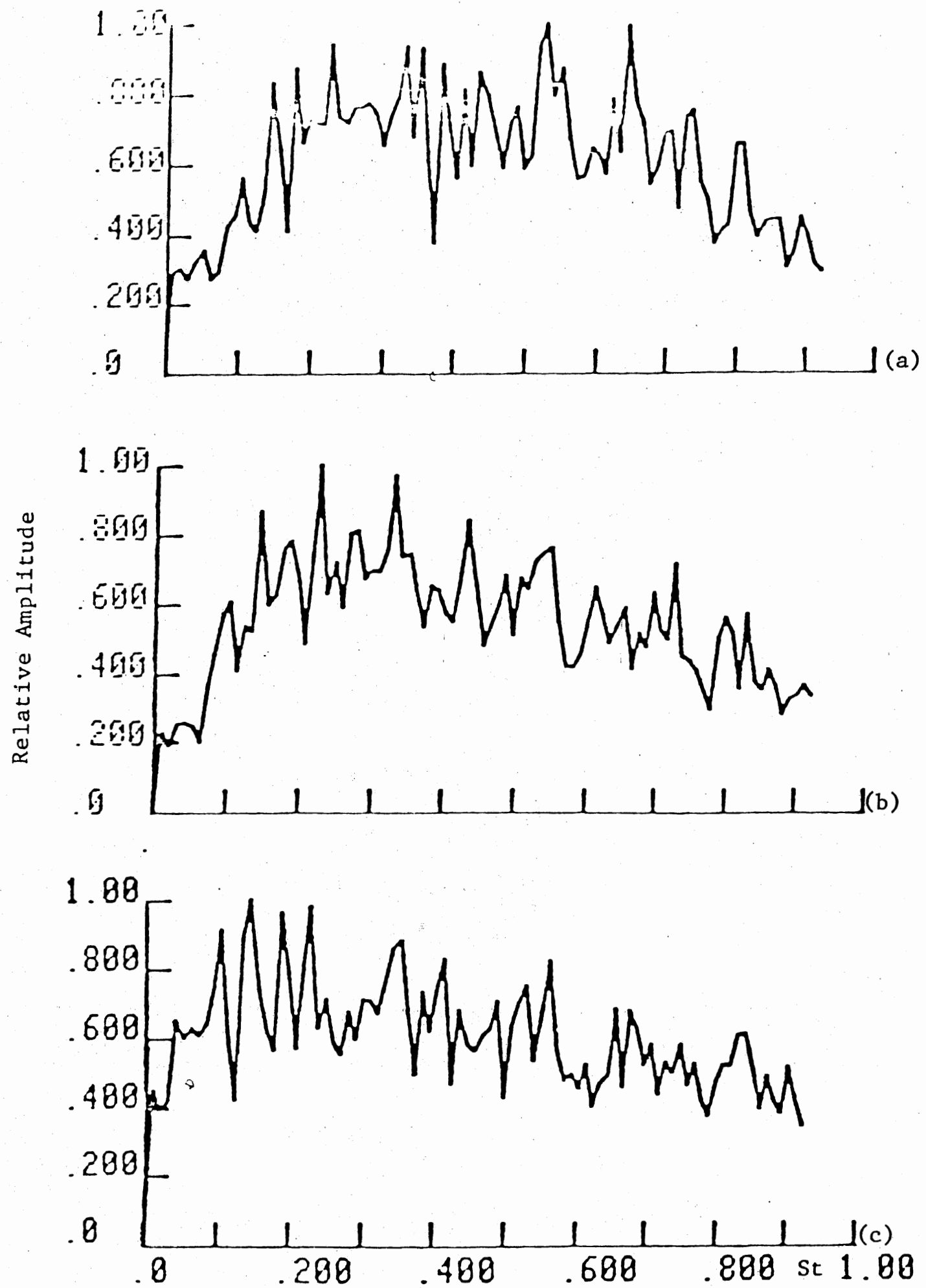

Figure 25. Microphone Spectra Measured at (a) $R / d=30$

(b) $\mathrm{R} / \mathrm{d}=50$ (c) $\mathrm{R} / \mathrm{d}=80$ from a $\mathrm{M}=2.1$

Jet $(\operatorname{Re}=70,000)$ 
APPENDIX B

TABLE 
TABLE I

NONLINEAR PROPAGATION RESULTS

\begin{tabular}{|c|c|c|c|c|c|c|c|c|c|c|}
\hline 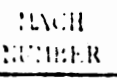 & 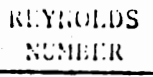 & $\begin{array}{c}\text { EXCITATION } \\
\text { St } \\
\end{array}$ & $\begin{array}{l}\text { TAPE } \\
\text { SEGMENT } \\
\end{array}$ & $\begin{array}{r}\because 2 . C . \\
\text { DECREASE } \\
\end{array}$ & \multicolumn{3}{|c|}{ WAVE STEEPENING FACTOR } & \multicolumn{3}{|c|}{$\begin{array}{l}\text { REL. 2NU HARYUNIC AMAPLITLDE. } \\
\text { R/d }=30 / 2 / d=50 \mid R / d=80\end{array}$} \\
\hline $\begin{array}{l}2.5 \\
2.5\end{array}$ & $\begin{array}{l}8,700 \\
8,700\end{array}$ & $\begin{array}{l}0.16 \\
0.16\end{array}$ & $\begin{array}{l}A \\
B\end{array}$ & $\begin{array}{l}0 \% \\
0 \%\end{array}$ & $\begin{array}{l}0.68 \\
0.69\end{array}$ & $\begin{array}{l}0.60 \\
0.63\end{array}$ & $\begin{array}{l}0.47 \\
0.45\end{array}$ & $\begin{array}{l}0.29 \\
0.35\end{array}$ & $\begin{array}{l}0.31 \\
0.42\end{array}$ & $\begin{array}{l}0.34 \\
0.43\end{array}$ \\
\hline $\begin{array}{l}2.5 \\
2.5\end{array}$ & $\begin{array}{l}8,700 \\
8,700\end{array}$ & - & $\begin{array}{l}\text { A } \\
\text { B }\end{array}$ & $\begin{array}{l}7 \% \\
6 \%\end{array}$ & $\begin{array}{l}0.88 \\
0.89\end{array}$ & $\begin{array}{l}0.85 \\
0.77\end{array}$ & $\begin{array}{l}0.89 \\
0.90\end{array}$ & $\begin{array}{l}0.12 \\
0.13\end{array}$ & $\begin{array}{l}0.32 \\
0.29\end{array}$ & $\begin{array}{l}0.58 \\
0.30\end{array}$ \\
\hline $\begin{array}{l}2.1 \\
2.1\end{array}$ & $\begin{array}{l}10,000 \\
10,000\end{array}$ & $\begin{array}{l}0.19 \\
0.19\end{array}$ & $\begin{array}{l}A \\
B\end{array}$ & $\begin{array}{l}0 \% \\
0 \%\end{array}$ & $\begin{array}{l}0.60 \\
0.64\end{array}$ & $\begin{array}{l}0.51 \\
0.61\end{array}$ & $\begin{array}{l}0.47 \\
0.44\end{array}$ & $\begin{array}{l}0.28 \\
0.27\end{array}$ & $\begin{array}{l}0.39 \\
0.28\end{array}$ & $\begin{array}{l}0.43 \\
0.34\end{array}$ \\
\hline $\begin{array}{l}2.1 \\
2.1 \\
2.1\end{array}$ & $\begin{array}{l}10,000 \\
10,000 \\
10,000\end{array}$ & $\overline{-}$ & $\begin{array}{l}\text { A } \\
\text { B } \\
\text { C }\end{array}$ & $\begin{array}{l}0 \% \\
0 \% \\
0 \%\end{array}$ & $\begin{array}{l}0.72 \\
0.63 \\
0.72\end{array}$ & $\begin{array}{l}0.74 \\
0.99 \\
0.63\end{array}$ & $\begin{array}{l}0.86 \\
0.99 \\
0.78\end{array}$ & $\begin{array}{l}0.11 \\
0.19 \\
0.18\end{array}$ & $\begin{array}{l}0.10 \\
0.09 \\
0.21\end{array}$ & $\begin{array}{l}0.11 \\
0.07 \\
0.22\end{array}$ \\
\hline $\begin{array}{l}2.5 \\
2.5\end{array}$ & $\begin{array}{l}50,0 \cup 0 \\
50,010\end{array}$ & $\begin{array}{l}0.29 \\
0.29\end{array}$ & $\begin{array}{l}\text { A } \\
\text { B }\end{array}$ & $\begin{array}{r}-1 \% \\
0 \%\end{array}$ & $\begin{array}{l}1.14 \\
1.04\end{array}$ & $\begin{array}{l}0.92 \\
0.87\end{array}$ & $\begin{array}{l}1.06 \\
1.01\end{array}$ & $\begin{array}{l}0.53 \\
0.42\end{array}$ & $\begin{array}{l}0.74 \\
0.61\end{array}$ & $\begin{array}{l}0.39 \\
0.27\end{array}$ \\
\hline $\begin{array}{l}2.5 \\
2.5\end{array}$ & $\begin{array}{l}50,0100 \\
50,000\end{array}$ & - & $\begin{array}{l}\text { A } \\
\text { B }\end{array}$ & $\begin{array}{l}16 \% \\
17 \%\end{array}$ & $\begin{array}{l}1.11 \\
1.14\end{array}$ & $\begin{array}{l}0.93 \\
0.99\end{array}$ & $\begin{array}{l}1.05 \\
0.99\end{array}$ & & . & \\
\hline $\begin{array}{l}2.1 \\
2.1 \\
2.1\end{array}$ & $\begin{array}{l}70,000 \\
70,000 \\
70,000\end{array}$ & $\begin{array}{l}0.19 \\
0.19 \\
0.19\end{array}$ & $\begin{array}{l}A \\
B \\
C\end{array}$ & $\begin{array}{r}0 \% \\
16 \% \\
0 \%\end{array}$ & $\begin{array}{l}1.09 \\
1.09 \\
1.07\end{array}$ & $\begin{array}{l}1.09 \\
1.04 \\
1.00\end{array}$ & $\begin{array}{l}1.04 \\
1.04 \\
1.07\end{array}$ & & & \\
\hline $\begin{array}{l}2.1 \\
2.1 \\
2.1 \\
2.1\end{array}$ & $\begin{array}{l}70,000 \\
70,600 \\
70,600 \\
70,000\end{array}$ & $\begin{array}{l}- \\
- \\
-\end{array}$ & $\begin{array}{l}A \\
B \\
C \\
D\end{array}$ & $\begin{array}{r}14 \% \\
8 \% \\
20 \% \\
18 \%\end{array}$ & $\begin{array}{l}1.09 \\
1.05 \\
1.05 \\
1.10\end{array}$ & $\begin{array}{l}1.07 \\
1.01 \\
1.03 \\
1.02\end{array}$ & $\begin{array}{l}1.00 \\
1.04 \\
1.00 \\
1.09\end{array}$ & & & \\
\hline
\end{tabular}




$$
\begin{gathered}
\text { VITA } \\
\text { James Anthony Gallagher } \\
\text { Candidate for the Degree of } \\
\text { Master of Science }
\end{gathered}
$$

Thesis: EXPERIMENTS ON THE NONLINEAR CHARACTERISTICS OF NOISE PROPAGATION FROM LOW AND MODERATE REYNOLDS NUMBER SUPERSONIC JETS

Major Field: Mechanical Engineering

Biographical:

Personal Data: Born in Strabane Co. Tyrone, North Ireland, December 16,1957

Education: Received the Bachelor of Science degree in Aeronautical Engineering from the University of Manchester, England, in June, 1979; completed the requirements for the Master of Science degree at Oklahoma State University in May, 1981.

Honors: Cities Service Scholarship, Phi Kappa Phi

Professional Societies: American Institu:e of Aeronautics and Astronautics. National Society of Professional Engineers and Royal Aeronautical Society 